\title{
O Que se Discute sobre Leitura e Ensino de Ciências na Educação Básica: uma Análise das Pesquisas Apresentadas no ENPEC
}

\section{What is Discussed about Reading and Teaching of Science in Basic Education: an Analysis of Studies Presented at ENPEC}

(D) Caroline Batista Silva de Souza, Luciana Sedano

\section{Palavras-chave \\ Leitura; \\ Ensino de Ciências; \\ Educação Básica; \\ Levantamento \\ Bibliográfico; \\ ENPEC.}

Resumo Estudos que abordam a relação entre leitura e ensino de Ciências podem ser encontrados desde a década de 1980, sendo inegável o papel importante que a leitura possui em todas as áreas do conhecimento. Diante disso, esta pesquisa investigou como o trabalho com a leitura e o ensino de Ciências na Educação Básica se apresenta nas publicações das edições do Encontro Nacional de Pesquisa em Educação em Ciências (ENPEC), objetivando compreender a relação apresentada entre o trabalho com a leitura e o ensino de Ciências. Para isso, realizamos uma pesquisa qualitativa e do tipo bibliográfica nas atas das edições do ENPEC de 1997 a 2019, buscando por trabalhos que tratavam da temática "leitura e ensino de Ciências". Entre os trabalhos encontrados, 63 discutiam essa temática, sendo 28 deles referentes à Educação Básica. A pesquisa possibilitou construir um panorama das investigações realizadas e divulgadas sobre o trabalho com leitura e ensino de Ciências nesse evento, apontando que a discussão está presente em poucas pesquisas apresentadas. A análise denotou, ainda, que as tendências dos trabalhos encontrados estão direcionadas para diversas vertentes, desde o uso exclusivo do livro didático como único suporte para a atividade de leitura até discussões sobre a inquestionável importância da leitura no processo da Alfabetização e Letramento científico, denunciando a enorme preocupação da segregação entre leitura e ensino de Ciências. 
Keywords Abstract Studies that address the relationship between reading Reading; and teaching of science date back to the 1980s, which demonstrate Science Teaching; the undeniably critical role that reading plays throughout all fields Basic Education; of knowledge. Therefore, this research investigated how reading and Bibliographic teaching of science is assessed in Basic Education, using publications Research; from editions of the National Meeting of Research in Science Education ENPEC. (ENPEC). In order to understand the relationship between reading and teaching of science, we conducted a qualitative and bibliographic analysis of the minutes of the ENPEC editions from 1997 to 2019 on this topic. The query returned 63 papers, of which 28 referred to Basic Education. The results allowed to map the investigations on reading and teaching of science in this event, suggesting that this topic is not widely discussed among the studies in the field. On the other hand, we found that the studies analyzed use several different approaches, with discussions ranging from the exclusive use of textbooks for reading activities to the undeniable importance of reading in the process of scientific literacy, which express the concern about the segregation between reading and teaching of science.

\section{Introdução}

A leitura tem sido objeto de estudo de inúmeros autores, pesquisas e publicações. Bianualmente acontece - desde o ano de 1978 - o Congresso de Leitura do Brasil (COLE) promovido pela Associação de Leitura do Brasil (ABL) que tem reunido pessoas para discutir temas relativos à leitura e à escrita, a partir de diversas perspectivas teóricas e metodológicas, ampliando e multiplicando os sentidos dessas práticas.

Além disso, as discussões sobre leitura são realizadas em diferentes eventos da área de educação e de ensino. Um deles é o Encontro Nacional de Pesquisa em Educação em Ciências (ENPEC), evento bienal promovido desde 1997 pela Associação Brasileira de Pesquisa em Educação em Ciências (ABRAPEC). No entanto, o estudo da leitura no ensino de Ciências antecede o ENPEC. Pesquisas nacionais e internacionais como Cook e Mayer (1988), Green e Meyer (1991), Guzzetti, Snyder e Glass (1992), Koch e Eckstein (1991), Ricon e Almeida (1991) demonstram que já havia trabalhos focados em investigar a leitura no ensino de Ciências sendo desenvolvidos desde a década de 1980.

Investigações sobre linguagem e leitura no ensino de Ciências continuam sendo realizadas sob diversas perspectivas. Na presente pesquisa, foi possível destacar trabalhos recentes que investigaram a relação entre linguagem, leitura e ensino de Ciências (Ardasheva et al., 2015; Ariely et al., 2019; Bratkovich, 2018; Hayden \& Eades-Baird, 2016; Heineke et al., 2019; Jiménez \& Brocos, 2015; Özdem et al., 2017; Silveira et al., 2015).

As pesquisas de Ariely et al. (2019) e Bratkovich (2018) defendem a importância do uso da linguagem científica em textos trabalhados em aulas de Ciências. Em seus artigos, os autores discutem o trabalho com leitura, visando à compreensão e apropriação da linguagem científica. 
Os estudos de Jiménez e Brocos (2015), Özdem et al. (2017) abordaram o papel da argumentação no ensino de Ciências. Essas pesquisas discutem que a argumentação está enquadrada nas práticas envolvidas na construção do conhecimento e, portanto, deve possuir um lugar de atenção e estudo nas aulas de Ciências.

Ardasheva et al. (2015) exploraram a noção de ensino de Ciências para alunos de língua inglesa. Ao trabalhar simultaneamente a linguagem e conteúdo científico, os pesquisadores desenvolveram os três processos de aprendizagem com os estudantes: aprender por meio da linguagem da Ciência; aprender sobre a linguagem da Ciência e viver a linguagem da Ciência. Do mesmo modo, Heineke et al. (2019) analisaram como a formação de professores baseada em campo promove e influencia o desenvolvimento de especialização profissional para o ensino de bilíngues emergentes em salas de aula de Ciências do ensino médio. Com isso, os autores exploraram os esforços de desenvolvimento profissional com professores em serviço com foco na educação científica para bilíngues emergentes.

Alguns estudos nacionais também abordam sobre a temática leitura e ensino de Ciências a partir da discussão do papel da leitura e do texto em aulas de Ciências (Araújo et al., 2018; Almeida, 2018; Setlik \& Higa, 2019). Silveira et al. (2015) investigaram a problemática da mediação pedagógica na leitura de textos didáticos de Ciências em sala de aula, argumentando a favor da leitura de textos de Ciências para se aprender Ciências, e sobre o papel central que a mediação docente desempenha nesse processo.

Para conduzir nossa investigação, fizemos uma busca dos trabalhos publicados sobre a temática nas edições do ENPEC (1997-2019). Organizamos e analisamos os dados de acordo com a metodologia da Análise de Conteúdo (Bardin, 2009; Mendes \& Miskulin, 2017), baseando-nos também nas etapas de investigação de Francisco e Queiroz (2005), que defendem uma metodologia de trabalho embasada na interação entre o pesquisador e o objeto de pesquisa. De acordo com o objetivo traçado para este artigo, que é analisar como o trabalho com a leitura e o ensino de Ciências na Educação Básica se apresenta nas publicações das edições do ENPEC de 1997 a 2019, selecionamos e analisamos os trabalhos que traziam o enfoque didático para leitura, ou seja, propunham alguma atividade ou análise de texto nas aulas de Ciências e, ainda, fossem realizados na Educação Básica, por se tratar do nível de ensino fundante para a socialização, início da escolarização e formação do estudante.

Mesmo com a heterogeneidade das investigações sobre leitura e ensino de Ciências, as pesquisas são consensuais em relação à importância da discussão e problematização do papel que o trabalho com a leitura assume nas aulas de Ciências. A preocupação com a segregação estabelecida entre as áreas de conhecimento é outro aspecto importante exposto nos trabalhos analisados. A leitura é equivocadamente vista como sendo responsabilidade apenas da área de Linguagem, mais especificamente da disciplina de Língua Portuguesa. 


\section{O papel da leitura no ensino de Ciências}

Cafiero (2005) afirma que a "leitura é uma atividade ou um processo cognitivo de construção de sentidos realizado por sujeitos sociais inseridos num tempo histórico, numa dada cultura" (p. 17). Por isso, a leitura não deve ser compreendida apenas como um ato mecânico, como uma decodificação de letras e fonemas. Nesse processo, o leitor relaciona o que lê com os seus conhecimentos prévios, estabelece conexões, constrói sentidos e, ao compreender o texto, é capaz de criticar e se posicionar. Assim, de acordo com Kleiman (2004) e Soares (2008), ser leitor é necessariamente ser social, o que implica compreender cada leitor desse modo.

Cafiero (2005) entende a leitura como um processo que vai além da decodificação e que comporta a compreensão e a atribuição de sentidos ao que se lê. Também nessa perspectiva, Coscarelli (2002) entende a leitura como um processo além da decodificação e aponta que conceber a leitura como um ato mecânico dificulta o trabalho do professor em ajudar os alunos a desenvolverem estratégias de leitura.

Ao defender o trabalho com a leitura no ambiente escolar, Lerner (2002) aponta que as práticas pedagógicas precisam garantir "uma semelhança fundamental entre o que se ensina e o objeto ou prática social que se pretende que os alunos aprendam. A versão escolar da leitura e da escrita não deve afastar-se demasiado da versão social não-escolar" (p. 35). Por isso, o trabalho deve ser feito de forma contextualizada, ou seja, deve estar relacionado com os aspectos vividos fora dos muros da escola.

Diante destes pressupostos sobre a leitura e o seu lugar social, principalmente na interação do leitor enquanto sujeito com o texto, cabe-nos aqui situar as Ciências e o que entendemos dessa relação na Educação em Ciências também.

Não se pode ignorar o papel e a influência das Ciências em nosso dia a dia. A todo o momento, direta ou indiretamente, a Ciência e seus saberes fazem parte de nossas vidas, seja quando temos contato com adventos tecnológicos desenvolvidos com auxílio do conhecimento de fenômenos do mundo natural, seja quando interagimos com a sociedade, ou mesmo quando estamos em contato com os ambientes naturais (Azevedo \& Scarpa, 2017; Delizoicov et al., 2002).

Diante da necessidade emergente de formar alunos para atuarem de maneira ativa na sociedade atual, largamente cercada por artefatos da sociedade científica e tecnológica, a Alfabetização Científica (AC) deve ser objetivo central do ensino de Ciências (Sasseron \& Carvalho, 2016). Segundo Sasseron (2015), a AC "revela-se como a capacidade construída para a análise e a avaliação de situações que permitam ou culminem com a tomada de decisões e o posicionamento" (p. 56). Do mesmo modo, Sasseron e Carvalho (2008) declara que a Alfabetização Científica é contínua, não se encerra no tempo e não se encerra em si mesma. Assim como a própria Ciência, a Alfabetização Científica deve estar sempre em construção, englobando novos conhecimentos pela análise e em decorrência de novas situações. 
Ao vislumbrarmos a leitura como componente importante no processo de Alfabetização Científica, compreendemos a importância de discuti-la. Entretanto, o entendimento sobre a concepção de leitura pode variar de acordo com o contexto, a linha de pesquisa ou a área de conhecimento. Apesar da variação, a maioria das vertentes teóricas a considera como um caminho inquestionável para o saber e para o desenvolvimento do pensamento; há concordância também sobre a importância da compreensão do significado de algo que se lê (Oliveira et al., 2004).

Nas discussões relacionadas ao ensino de Ciências, Norris e Phillips (2003) destacam a importância da leitura e da escrita para o fazer Ciência, "leitura e escrita são indissociáveis e ligadas à própria natureza da Ciência e, por extensão, para a aprendizagem da Ciência” (p. 226, tradução nossa). Esses autores apresentam também o conceito de alfabetização no seu sentido fundamental, questionando como os leitores irão lidar com os textos, quais recursos do texto usam e como usá-los para determinar $\mathrm{o}$ (s) significado(s) do texto em relação com o letramento científico.

Em aulas de Ciências que objetivam a problematização e um ensino que promova a Alfabetização Científica, o texto exerce a função de aproximar o aluno dos conceitos científicos. Além da aproximação com o procedimento da leitura, podemos afirmar que o texto, quando inserido no ambiente do fazer Ciência, provoca o educando a refletir sobre a discussão proposta, pensar criticamente, tomar posição embasada na relação com o que é apresentado no texto e seus conhecimentos prévios.

Vale ressaltar que é muito importante que o ensino de Ciências possibilite que os alunos desenvolvam a leitura tendo contato com diversos gêneros textuais, pois isso permitirá a eles, além de conhecerem o universo científico, serem capazes de estabelecer de forma crítica e reflexiva a conexão com outros gêneros lidos (Pereira \& Lima, 2018; Solé, 1996).

A leitura também se apresenta como imprescindível para a apropriação da linguagem científica. Mortimer (1998), ao discutir sobre as construções linguísticas usadas pelos alunos, aponta a enorme necessidade de se trabalhar a linguagem científica na aprendizagem de Ciências, pois ao se apropriar dela, o estudante assegura a evolução dos significados atribuídos à Ciência e se torna capaz de operar os seus conceitos (Wenzel, 2017).

A apropriação da linguagem científica é essencial para que não se perpetuem as visões deformadas da Ciência. Dessa forma, a leitura em aulas de Ciências pode contribuir para atenuar as concepções inadequadas sobre o trabalho científico e para que a Ciência não seja vista como empírico-indutivista, ateórica, algorítmica, infalível, elitista, aproblemática e livre de contextos (Azevedo \& Scarpa, 2017; Pérez et al., 2001; Scheid et al., 2009). Dessa forma, os textos utilizados nas aulas de Ciências, após adaptações para fins didáticos, muitas vezes acabam por sofrer interferências que descaracterizam traços próprios da linguagem científica (Ariely et al., 2019), distanciando o estudante da possibilidade de construção do conhecimento adequado sobre a Ciência e o trabalho científico. 
Ainda em uma tentativa de diversificar as propostas de ensino em aulas de Ciências, costuma-se subestimar o valor da leitura e da escrita frente às atividades manipulativas, principalmente a leitura que, muitas vezes, é entendida como um processo automático (Nigro, 2010; 2012). Estudos realizados em nosso grupo de pesquisa (nome do grupo/ CAPES) coadunam com as discussões de Nigro (2010; 2012), principalmente no que tange à identificação da importância de inserir, em um contexto didático de ensino de Ciências, o trabalho com a leitura que incentive a construção da compreensão leitora a partir do ensino por investigação como abordagem didática (Sasseron, 2015). Assim, o trabalho com leitura nas aulas de Ciências não ficará deslocado do contexto didático de ensino de Ciências que se quer oportunizar (Carvalho et al., 2013; Sedano et al., 2019). Este ensino deve responder ao objetivo maior de promoção da Alfabetização Científica e, como tal, aos objetivos de aprendizagem que a AC quer proporcionar.

Conforme Yore et al. (2003), a pesquisa sobre leitura e escrita no ensino de Ciências perdeu espaço para os estudos sobre as atividades práticas, na tentativa de desenvolver um ensino menos centrado nas apostilas e manuais didáticos, e mais voltado para a experimentação. Porém, esses autores defendem que as atividades práticas sem o trabalho com o pensamento e o raciocínio não se mostraram eficazes.

Os trabalhos de Gomes (2017), Camilo e Ometto (2017) discutem que a promoção de uma prática de leitura cuja finalidade se volta para explicar conteúdos específicos das disciplinas e para responder ou corrigir exercícios evidencia uma concepção de linguagem voltada para busca de informações no texto, quando poderia privilegiar o processo de interação, de interlocução entre os sujeitos. Os autores defendem o aprendizado da leitura e o acesso a uma formação que dê ao aluno possibilidades de praticar na escola e na vida o que é próprio do ser humano: a atitude responsiva ativa, que seja possibilitada desde os anos iniciais da escolarização, estimulando um modo de leitura que objetive a compreensão, a réplica, o diálogo entre os sujeitos envolvidos nessa prática cultural que é a leitura.

A discussão sobre os gêneros textuais presentes nas aulas de Ciências e seus impactos no trabalho com a leitura no ensino de Ciências se faz presente nos textos de Almeida (2018) e Silva (2019), que problematizam o predomínio de gêneros do domínio escolar, discutindo que aqueles que se manifestam em sala de aula são os que obedecem às restrições normativas da instituição. Os trabalhos enfatizam a importância do trabalho com textos de divulgação científica que despertem o prazer, a curiosidade e o mistério escondidos nas possibilidades de leitura, apontando as contribuições da leitura no ensino de Ciências, tais como: ampliação da visão dos estudantes diante do mundo em constante mudança; construção do entendimento de conceitos e vocabulário científico no leitor; compreensão da natureza das Ciências, entre outras.

Encontramos ainda na literatura exemplos e discussões sobre a importância do trabalho com a leitura nas aulas de Ciências desde os primeiros anos de escolarização (Almeida, 2018; Franco \& Fernandes, 2017). Ao descrever e avaliar o caráter mediador da literatura infantil no ensino de Ciências em uma turma do $1^{\text {o }}$ ciclo do ensino 
fundamental, a investigação de Lana e Silva (2019) denota que a literatura infantil é capaz de despertar o interesse nas crianças por possibilitar a abstração e a imaginação, sendo, por esse motivo, um mediador importante para a aprendizagem em Ciências.

Com o objetivo de resgatar o valor da leitura nas aulas de Ciências, e das possibilidades de trabalho, realizamos um levantamento bibliográfico das pesquisas sobre o trabalho com leitura e ensino de Ciências publicadas nas edições do ENPEC (1997-2019), o que contribuiu para um olhar mais abrangente sobre a temática em âmbito nacional.

\section{Percurso Metodológico}

Esta pesquisa analisou os trabalhos publicados nos anais do Encontro Nacional de Pesquisa em Educação em Ciências (ENPEC) de 1997 a 2019. Investigamos os trabalhos completos que tratavam do tema "leitura e ensino de Ciências". A escolha do ENPEC como fonte dos dados justifica-se pelo fato de esse evento ser um dos principais encontros nacionais em que podemos encontrar os resultados de produções científicas sobre o ensino de Ciências. Com 12 edições já realizadas, visando reunir pesquisadores em Educação em Ciências para discutir trabalhos de pesquisas recentes e tratar de temas de interesse da área, o evento consolidou-se no cenário científico nacional.

No primeiro momento, levantamos a bibliografia atualizada, pesquisando em periódicos de referência nas áreas de Educação e de Ensino de Ciências, analisando artigos que tratassem sobre o tema da Leitura nas aulas de Ciências. Com essas referências, embasamos teoricamente o nosso trabalho. Posteriormente, buscamos os trabalhos publicados e disponíveis em meio eletrônico ${ }^{1}$ nos anais das edições do ENPEC de 1997 a 2019. Ao acessar o endereço, o pesquisador é redirecionado a outro site, pois cada edição está em um endereço eletrônico específico.

Iniciamos a pesquisa dos trabalhos por meio dos descritores leitura, leitor, leitores, alfabetização científica, compreensão leitora e formação do leitor. Investigamos títulos, palavras-chave e resumos, quando esses três critérios de busca não foram suficientes para classificá-los, lemos o texto na íntegra. Essa primeira busca resultou em 63 trabalhos e, a partir desta etapa de organização dos dados, realizamos a leitura dos textos completos, buscando compreender como cada um abordava a prática da leitura no ensino de Ciências na Educação Básica.

A primeira leitura realizada, caracterizada como leitura flutuante, de acordo com a metodologia da Análise de Conteúdo (Bardin, 2009; Mendes \& Miskulin, 2017), destacou, entre os 63 textos pré-selecionados, os que dialogavam diretamente com o objetivo traçado para esta pesquisa. Buscávamos análises e discussões sobre o trabalho com leitura nas aulas de Ciências na Educação Básica, e a leitura flutuante nos permitiu reduzir o corpus de análise para 28 trabalhos. Essa diminuição se deu porque os outros textos tratavam do objeto de pesquisa deste artigo - leitura e ensino de Ciências —, porém as discussões propostas se distanciavam dos nossos objetivos, porque consideravam outros níveis de ensino, versavam sobre formação de professores ou abordavam outras questões que não dialogavam diretamente com o ensino de Ciências na Educação Básica.

1 http://www.abrapec.ufsc.br/enpecs-anteriores/ 
Após a leitura flutuante, os trabalhos foram novamente lidos e estudados na íntegra e, em diálogo com o referencial teórico adotado, alguns eixos temáticos foram elencados para que, a partir deles, as categorias de análise pudessem ser construídas.

Além da Análise de Conteúdo proposta como metodologia de organização e análise dos dados para esta pesquisa, nos baseamos também nas etapas de investigação propostas por Francisco e Queiroz (2005), que estabeleceram uma metodologia de trabalho baseada na interação entre pesquisador e objeto de pesquisa, considerando que o pesquisador deve analisar o texto e classificá-lo com a maior clareza possível, identificando o objeto que investiga no trabalho. Tendo os anais dos encontros em foco, a investigação ocorreu de acordo com as seguintes etapas fundamentadas em Francisco e Queiroz (2005):

1. Seleção e leitura dos trabalhos completos que apresentassem a temática "leitura e Ensino de Ciências";

2. Classificação dos trabalhos: ano de publicação, público-alvo, local de publicação e foco temático;

3. Análise dos resultados obtidos e elaboração de tabelas para auxiliar nas conclusões sobre as principais tendências observadas.

Em observância aos dados que emergiram dos trabalhos do ENPEC, em diálogo com a teoria estudada para esta pesquisa, sintetizamos esses dados em eixos temáticos, cuidando para que não houvesse confluência entre eles e, ao mesmo tempo, que as principais propriedades dos trabalhos pudessem ser preservadas. Construímos 22 eixos temáticos: a importância do leitor como sujeito social; leitura coletiva; apropriação da linguagem da Ciência; letramento científico; leitura de textos científicos; técnicas de leitura; atribuir sentido à leitura/produção de sentidos dos estudantes em suas leituras; modelo de leitura; leitura recreativa; literatura infantil; defasagem terminológica e conteudística do texto didático; leitura crítica; leitura interativa-construtiva dos estudantes; leitura de textos de não ficção em aulas de Ciências; leitura como ferramenta de interação social; estratégias de leitura em sintonia com uma perspectiva progressista; mediação didática na leitura; compreensão leitora; formação do leitor autônomo e competente; texto didático; linguagem empregada nos textos didáticos; engajamento na leitura.

Para a construção das categorias de análise, os eixos temáticos foram reorganizados de acordo com sua similaridade teórica e, a partir deles, compomos quatro categorias, sendo elas: categoria 1: Leitura como construção social, para além da decodificação; categoria 2: Estratégias de Leitura; categoria 3: A importância do trabalho com a leitura de diferentes gêneros textuais; categoria 4: A importância da leitura para a apropriação da linguagem científica. A reorganização dos eixos e as categorias às quais eles se relacionam estão demonstradas na Figura 1: 
Figura 1. Eixos Temáticos e Categorias de Análise

\begin{tabular}{|c|c|}
\hline Eixos Temáticos & Categorias de Análise \\
\hline $\begin{array}{l}\text { - a importância do leitor como sujeito social } \\
\text { - } \text { atribuir sentido à leitura/produção de sentidos } \\
\text { - los estudantes em suas leituras } \\
\text { - leitura crítica } \\
\text { - } \text { leitura como ferramenta de interação social } \\
\text { - formação do leitor autônomo e competente }\end{array}$ & $\begin{array}{l}\text { Categoria 1: Leitura como construção social, } \\
\text { para além da decodificação }\end{array}$ \\
\hline $\begin{array}{l}\text { - } \text { técnicas de leitura } \\
\text { - leitura coletiva } \\
\text { - } \text { modelo de leitura } \\
\text { - leitura interativa-construtiva dos estudantes } \\
\text { - estratégias de leitura em sintonia com uma } \\
\text { - } \text { perspectiva progressista } \\
\text { mediação didática na leitura }\end{array}$ & Categoria 2: Estratégias de Leitura \\
\hline $\begin{array}{ll}\text { - } & \text { leitura de textos de não ficção em aulas de } \\
\text { - } & \text { engâncias } \\
\text { - } & \text { leitura recreativa } \\
\text { - } & \text { literatura infantil } \\
\text { - } & \text { texto didático } \\
\end{array}$ & $\begin{array}{l}\text { Categoria 3: A importância do trabalho com } \\
\text { a leitura de diferentes gêneros textuais }\end{array}$ \\
\hline $\begin{array}{l}\text { - letramento científico } \\
\text { - } \text { apropriação da linguagem da Ciência } \\
\text { - leitura de textos científicos } \\
\text { - defasagem terminológica e conteudística do } \\
\text { texto didático } \\
\text { - linguagem empregada nos textos didáticos }\end{array}$ & $\begin{array}{l}\text { Categoria 4: A importância da leitura para a } \\
\text { apropriação da linguagem científica }\end{array}$ \\
\hline
\end{tabular}

Fonte: elaborado pelas autoras a partir de dados da pesquisa (2020).

Na primeira parte da análise, apresentamos um mapeamento para classificar os trabalhos considerando ano, edição, região e instituição. Na segunda, apresentamos apenas as categorias dos trabalhos que examinamos referentes à Educação Básica. Com isso, utilizamos dois trabalhos de cada categoria para explicitarmos e aprofundarmos a análise. 


\section{Análise dos dados}

A análise dos dados deste estudo será apresentada em tabelas, quadros e gráficos, a fim de demonstrarmos as constatações que obtivemos. A seguir, apresentamos um panorama geral dos trabalhos publicados nos anais do ENPEC sobre o trabalho com leitura e ensino de Ciências, classificando-os por região, ano, edição e instituição.

Figura 2. Total de trabalhos apresentados no ENPEC sobre a temática, distribuídos por Região

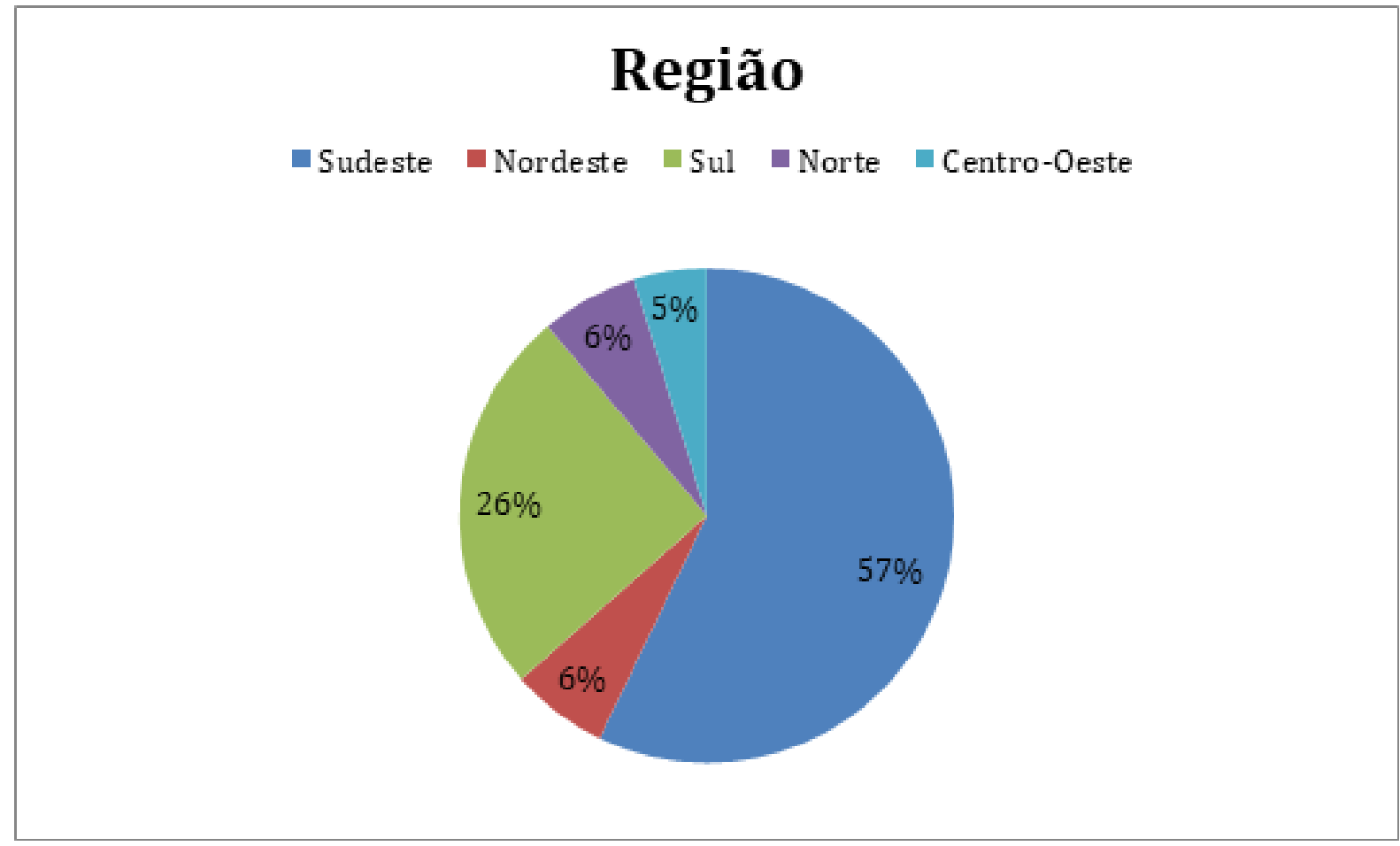

Fonte: elaborado pelas autoras a partir de dados da pesquisa (2020).

A Figura 2 aponta que os trabalhos sobre leitura e ensino de Ciências apresentados nas edições do ENPEC são predominantemente da região Sudeste. Uma hipótese possível para essa representatividade seria a relação com os eventos e projetos promovidos na região, que englobam discussões sobre a leitura. Exemplo disso é o COLE realizado pela ABL com o apoio da Unicamp, localizado na região Sudeste. Em seguida, os trabalhos sobre a temática se concentram na região Sul (26\%), seguida das regiões Norte, Nordeste e Centro-Oeste.

Apresentamos na Figura 3 a distribuição total dos trabalhos publicados nos anais do ENPEC (1997-2019), considerando ano, edição do evento e quantidade de trabalhos encontrados sobre a temática leitura e ensino de Ciências por região. 
Figura 3. Distribuição do total de trabalhos considerando ano, edição do evento, temática pesquisada e região

\begin{tabular}{|c|c|c|}
\hline Ano & Edição & Total de trabalhos sobre a temática por região \\
\hline 1997 & I & - \\
\hline 1999 & II & Sudeste -01 \\
\hline 2001 & III & Sudeste -01 \\
\hline 2003 & IV & Sudeste -02 \\
\hline 2005 & $\mathrm{~V}$ & Sudeste -05 \\
\hline 2007 & VI & $\begin{array}{l}\text { Sudeste }-03 \\
\text { Sul }-01\end{array}$ \\
\hline 2009 & VII & $\begin{array}{l}\text { Sul }-03 \\
\text { Norte }-01 \\
\text { Sudeste }-01 \\
\end{array}$ \\
\hline 2011 & VIII & $\begin{array}{l}\text { Sul - } 04 \\
\text { Sudeste - } 04 \\
\text { Norte - } 02 \\
\text { Nordeste - } 02\end{array}$ \\
\hline 2013 & IX & $\begin{array}{l}\text { Sudeste - } 08 \\
\text { Sul - } 06 \\
\text { Centro-Oeste - } 01\end{array}$ \\
\hline 2015 & $\mathrm{X}$ & $\begin{array}{l}\text { Sudeste - } 06 \\
\text { Nordeste - } 02 \\
\text { Sul - } 01 \\
\text { Centro-Oeste - } 01\end{array}$ \\
\hline 2017 & $\mathrm{XI}$ & $\begin{array}{l}\text { Sudeste }-06 \\
\text { Norte }-01 \\
\text { Centro-Oeste }-01\end{array}$ \\
\hline 2019 & XII & - \\
\hline \multicolumn{2}{|c|}{ Total } & 63 \\
\hline
\end{tabular}

Fonte: elaborado pelas autoras a partir de dados da pesquisa (2020).

Na Figura 3, podemos observar que a IX edição do ENPEC, realizada em 2013, em São Paulo, obteve o maior número de trabalhos relacionados à leitura e ensino de Ciências, com o total de 15 trabalhos. Ainda nessa edição, a região Sudeste obteve o maior número de publicações, contabilizando oito trabalhos no total. Esse dado pode ter relação com o crescimento da área de leitura como um todo, inclusive em decorrência da 
implementação de programas de pós-graduação, mestrados profissionais e acadêmicos nesse período. Também podemos atribuir esse dado ao fato de o evento ter sido realizado em São Paulo, e a tendência é que as pessoas da própria região submetam mais trabalhos ao evento, uma vez que a participação fica mais acessível, considerando a questão do deslocamento.

Observamos ainda que a primeira edição do ENPEC, realizada em Águas de Lindóia-SP, em 1997, não apresentou nenhum trabalho relacionado à leitura e ensino de Ciências. Esse dado pode derivar do fato de que, nessa época, a discussão sobre leitura era recente, como aponta Araújo e Carneiro (2017) ao afirmar que "os primeiros anos de 1980 marcam a preocupação acadêmica nos estudos de leitura. Os anos de 1990 consolidam as abordagens dos estudos sobre o tema" (p. 03).

É interessante destacarmos a XII edição do ENPEC, realizada em 2019, que apresentou um quantitativo de 973 trabalhos, sendo que nenhum abordou leitura e ensino de Ciências, mesmo possuindo linhas temáticas como "Linguagens e Discurso" e "Alfabetização Científica e Tecnológica; Abordagens CTS/CTSA" e linhas que discutiam leitura e escrita na Educação em Ciências. Esse fenômeno pode possuir relação com o tema central do encontro, que foi "Pesquisa em Educação em Ciências: Diferença, Justiça Social e Democracia”. Por sua vez, a IX edição contou com o maior número de trabalhos sobre leitura e ensino de Ciências, tendo como tema central "Perspectivas e desafios para a pesquisa em Educação em Ciências", em que foram apresentados trabalhos discutindo e problematizando a relação entre a leitura e o ensino de Ciências, como aponta o quantitativo de pesquisas relacionadas a essa temática. Entretanto, esse fato merece atenção, pois leitura e escrita não são somente objetivos extras e opcionais, mas aspectos fundamentais da Educação em Ciências (Andrade \& Martins, 2006). Acreditamos ainda que o trabalho com leitura e escrita nas aulas de Ciências (ou, como defendemos no recorte para esta pesquisa, o trabalho com leitura nas aulas de Ciências) é uma temática que poderia também permear as discussões sobre Diferença, Justiça Social e Democracia.

Na Figura 4, apresentamos o quantitativo de trabalhos apresentados no ENPEC e o total de trabalhos sobre a temática, considerando cada edição. 
Figura 4. Total de trabalhos apresentados no ENPEC e total de trabalhos sobre a temática

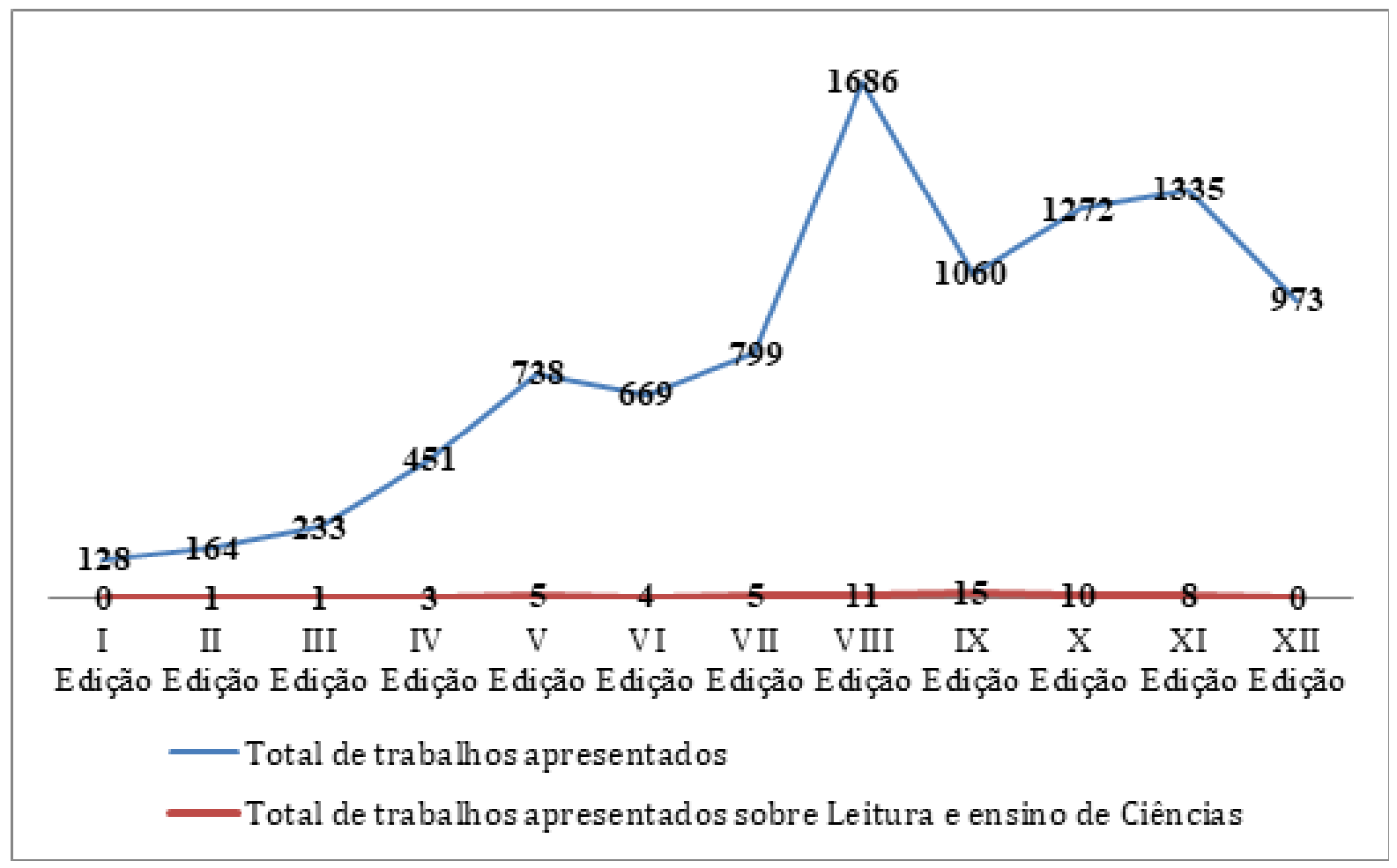

Fonte: elaborado pelas autoras a partir de dados da pesquisa (2020).

Entre 1999 e 2009, segunda e sétima edição, respectivamente, encontramos poucos trabalhos relacionados ao tema. Contudo, entre os anos 2011 e 2015, há um crescente aumento no que diz respeito ao número de trabalhos relacionados à leitura e ensino de Ciências. Entretanto, devemos observar que o número total de trabalhos apresentados também é crescente ao longo das edições.

Andrade et al. (2015), ao analisarem as produções do ENPEC de 1999 a 2013 e aplicarem o teste de correlação de Pearson, encontraram uma forte correlação entre o aumento dos trabalhos nos eventos e o aumento do número de trabalhos com o tema Leitura. A investigação conduzida pelos autores analisou nove edições do ENPEC sobre a temática leitura, buscando aspectos referentes à produtividade, autoria, filiação, temáticas abordadas, disciplinas, nível de ensino e referencial teórico e/ou metodológico. Os autores destacaram que a produção sobre o tema vem acompanhando o crescimento dos trabalhos enviados para o ENPEC. No entanto, a análise denotou que o aumento relacionado à temática acompanha o número de publicações apenas entre as edições XI, XII e XIII.

Um aumento percentual significativo pode ser observado na XI edição. Porém, nessa mesma edição, o número total de publicações relativo à edição anterior caiu drasticamente. Esse fato demonstra que não existiu essa relação entre o aumento de trabalhos apresentados e de trabalhos sobre leitura e ensino de Ciências. 
Figura 5. Distribuição de trabalhos por estado e edição

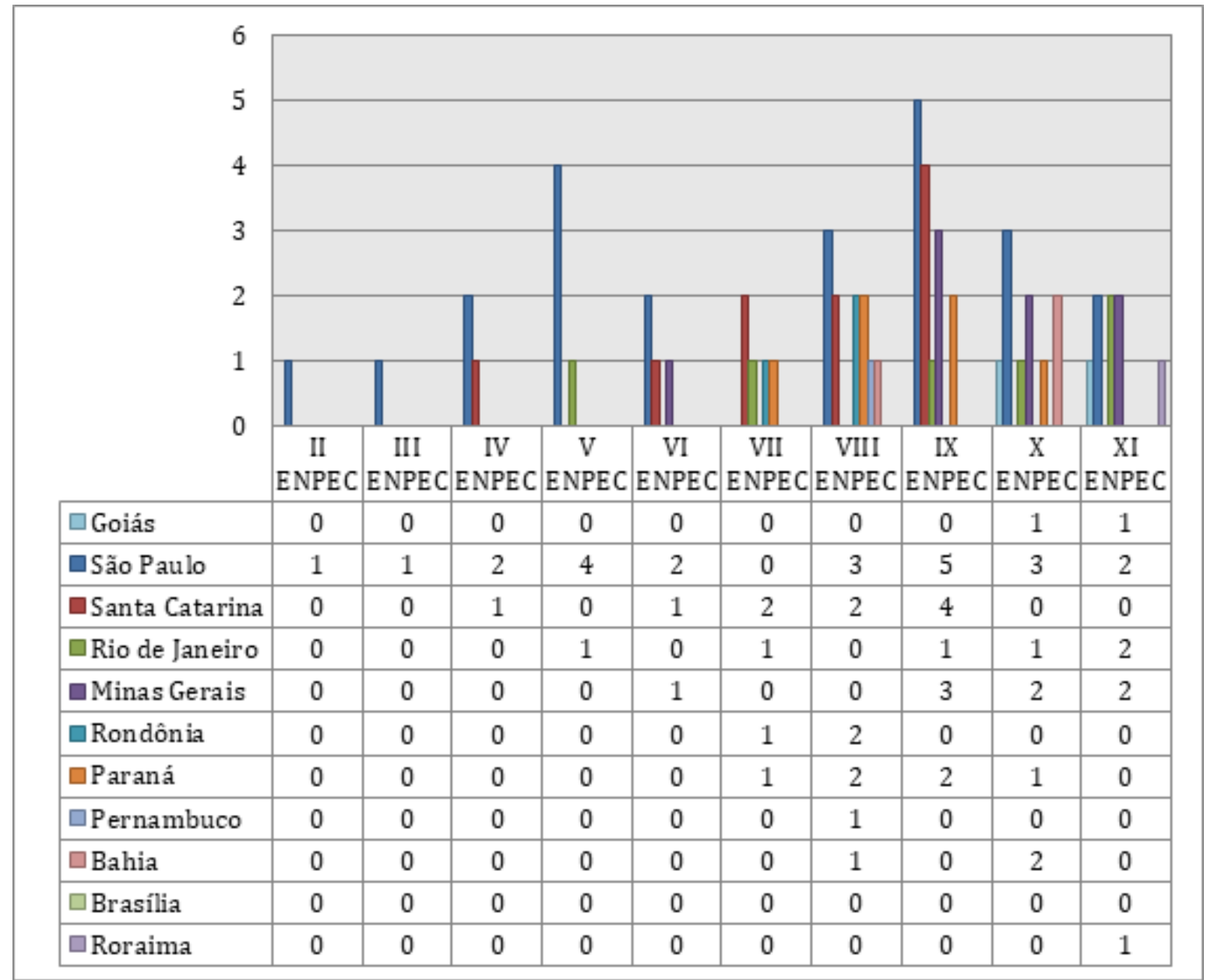

Fonte: elaborado pelas autoras a partir de dados da pesquisa (2020).

É notável que o estado de São Paulo contribuiu na maioria das edições, não colaborando com trabalhos sobre a temática apenas na edição XII. O estado de Santa Catarina foi o $2^{\circ}$ que mais colaborou com trabalhos sobre leitura e ensino de Ciências, considerando as edições do ENPEC de 1997 a 2019. A filiação institucional aponta o interesse de grupos de pesquisa e/ou programas de pós-graduação envolvidos com estudos relacionados ao tema. Pesquisas futuras podem investigar sobre as práticas desses grupos e/ou programas interessados no assunto, uma vez que isso pode ajudar a área a entender os padrões que foram construídos e seus interesses específicos no campo.

Ao investigarem a produção científica nas regiões brasileiras, Sidone et al. (2016) expõem que a questão geográfica está fortemente relacionada com as desigualdades de produção científica. Os autores discutem dados importantes como o fato de, em 2009, apenas sete universidades brasileiras da região Sudeste e Sul terem sido responsáveis por $60 \%$ dos trabalhos publicados em periódicos internacionais. 
Pode-se constatar que a Universidade Federal de Santa Catarina (UFSC) foi a instituição com maior quantidade de trabalhos relacionados ao tema leitura e ensino de Ciências nas edições do ENPEC de 1997 a 2019, computando 9 ao total (Figura 5). Em seguida, a Universidade Estadual de Campinas (UNICAMP) ocupa a $2^{\circ}$ posição como a Universidade que mais contribuiu com trabalhos sobre leitura e ensino de Ciências ao longo das edições do ENPEC.

Figura 6. Distribuição do total de trabalhos considerando ano, edição do evento, estado, instituição e quantidade de trabalhos por instituição

\begin{tabular}{|c|c|c|c|}
\hline Ano & Edição & Instituição & $\begin{array}{l}\text { Quantidade de } \\
\text { trabalhos }\end{array}$ \\
\hline 1999 & II & Universidade Metodista de Piracicaba - UNIMEP & 01 \\
\hline 2001 & III & Universidade Estadual Paulista - UNESP & 01 \\
\hline \multirow{2}{*}{2003} & \multirow{2}{*}{ IV } & Universidade Estadual Paulista - UNESP & 02 \\
\hline & & Universidade Federal de Santa Catarina - UFSC & 01 \\
\hline \multirow{4}{*}{2005} & \multirow{4}{*}{$\mathrm{V}$} & Universidade Estadual de Campinas - UNICAMP & 02 \\
\hline & & Universidade Federal do Rio de Janeiro - UFRJ & 01 \\
\hline & & $\begin{array}{l}\text { Faculdade de Educação da Universidade de São Paulo } \\
\text { - FEUSP }\end{array}$ & 01 \\
\hline & & Universidade Estadual Paulista - UNESP & 01 \\
\hline \multirow{4}{*}{2007} & \multirow{4}{*}{ VI } & $\begin{array}{l}\text { Pontifícia Universidade Católica de Minas Gerais - } \\
\text { PUC }\end{array}$ & 01 \\
\hline & & Universidade Federal de Santa Catarina - UFSC & 01 \\
\hline & & $\begin{array}{l}\text { Faculdade de Educação da Universidade de São Paulo } \\
\text { - FEUSP }\end{array}$ & 01 \\
\hline & & Universidade Estadual de Campinas - UNICAMP & 01 \\
\hline \multirow{4}{*}{2009} & \multirow{4}{*}{ VII } & Universidade Federal de Santa Catarina - UFSC & 02 \\
\hline & & Universidade Federal de Rondônia - UFR & 01 \\
\hline & & Universidade Federal do Rio de Janeiro - UFRJ & 01 \\
\hline & & Universidade Federal do Paraná - UFPR & 01 \\
\hline \multirow{8}{*}{2011} & \multirow{8}{*}{ VIII } & Universidade Federal de Santa Catarina - UFSC & 02 \\
\hline & & Universidade Estadual Paulista - UNESP & 02 \\
\hline & & Fundação Universidade Federal de Rondônia - UNIR & 02 \\
\hline & & Programa Universidade Sem Fronteira - SETI & 01 \\
\hline & & Universidade Federal de Pernambuco - UFPE & 01 \\
\hline & & Universidade Norte do Paraná - UNOPAR & 01 \\
\hline & & Universidade Federal do Recôncavo da Bahia - UFRB & 01 \\
\hline & & Universidade de São Paulo - USP & 01 \\
\hline
\end{tabular}

Fonte: elaborado pelas autoras a partir de dados da pesquisa (2020). 
Figura 6. Distribuição do total de trabalhos considerando ano, edição do evento, estado, instituição e quantidade de trabalhos por instituição (continuação)

\begin{tabular}{|c|c|c|c|}
\hline Ano & Edição & Instituição & $\begin{array}{l}\text { Quantidade de } \\
\text { trabalhos }\end{array}$ \\
\hline \multirow{9}{*}{2013} & \multirow{9}{*}{ IX } & Universidade Federal do Paraná - UFPR & 02 \\
\hline & & Universidade Estadual de Campinas - UNICAMP & 02 \\
\hline & & $\begin{array}{l}\text { Pontifícia Universidade Católica de Minas Gerais - } \\
\text { PUC }\end{array}$ & 01 \\
\hline & & Universidade Federal do Rio de Janeiro - UFRJ & 01 \\
\hline & & Escola Municipal Beatriz de Souza Brito - EMBSB & 01 \\
\hline & & $\begin{array}{l}\text { Universidade de Brasília - Faculdade de Educação - } \\
\text { UNB/FE }\end{array}$ & 01 \\
\hline & & Universidade Federal de Minas Gerais - UFMG & 02 \\
\hline & & Universidade Federal de Santa Catarina - UFSC & 03 \\
\hline & & Universidade de São Paulo - USP & 02 \\
\hline \multirow{8}{*}{2015} & \multirow{8}{*}{$\mathrm{X}$} & Universidade Estadual de Campinas - UNICAMP & 02 \\
\hline & & Universidade Estadual de Santa Cruz - UESC & 02 \\
\hline & & Instituto Federal de Goiás - IFG & 01 \\
\hline & & Universidade Federal de Juiz de Fora - UFJF & 01 \\
\hline & & $\begin{array}{l}\text { Universidade Federal do Rio de Janeiro - UFRJ/ } \\
\text { NUTES }\end{array}$ & 01 \\
\hline & & Universidade de São Paulo - USP & 01 \\
\hline & & Universidade Federal de Minas Gerais - UFMG & 01 \\
\hline & & Universidade Federal do Paraná - UFPR & 01 \\
\hline \multirow{8}{*}{2017} & \multirow{8}{*}{$\mathrm{XI}$} & $\begin{array}{l}\text { Universidade Federal do Rio de Janeiro - UFRJ/ } \\
\text { NUTES }\end{array}$ & 01 \\
\hline & & Universidade Estadual de Campinas - UNICAMP & 01 \\
\hline & & $\begin{array}{l}\text { Pontifícia Universidade Católica do Rio de Janeiro - } \\
\text { PUC-RIO }\end{array}$ & 01 \\
\hline & & Instituto Federal de Goiás - IFG & 01 \\
\hline & & Universidade de São Paulo - USP & 01 \\
\hline & & Universidade Federal de Juiz de Fora - UFJF & 01 \\
\hline & & Instituto Federal de Minas Gerais - IFMG & 01 \\
\hline & & Universidade Estadual de Roraima - UERR & 01 \\
\hline
\end{tabular}

Fonte: elaborado pelas autoras a partir de dados da pesquisa (2020).

Algumas instituições contribuíram apenas uma vez com trabalhos relacionados à temática, como: a Universidade Metodista de Piracicaba (UNIMEP) na primeira edição, em 1997; a Universidade Federal do Recôncavo da Bahia (UFRB) e a Universidade Norte do Paraná (UNOPAR) respectivamente, em 2011, na XIII edição do ENPEC; e a Universidade de Brasília - Faculdade de Educação (UNB/FE) na IX edição, em 2013. 
Ao ler todos os textos na íntegra, constatamos que nem todos que abordaram o tema leitura e ensino de Ciências traziam em suas discussões uma argumentação fundamentada sobre leitura ou sobre o ensino de Ciências. Percebemos que alguns trabalhos são mais próximos de um relato de experiência sobre o uso de um texto em uma aula de Ciências.

Tabela 1. Foco dos trabalhos que não possuíam a Educação Básica como contexto

\begin{tabular}{lc}
\hline \multicolumn{1}{c}{ Foco dos trabalhos } & Quantidade \\
\hline Docentes (trajetórias e experiências com a Leitura) & 13 \\
Análise do ENPEC & 04 \\
Alunos do ensino superior (experiências de leitura) & 10 \\
Textos do ENEM e pré-vestibulares & 04 \\
Salas de Leituras & 01 \\
Alfabetização Científica & 03 \\
TOTAL & $\mathbf{3 5}$ \\
\hline
\end{tabular}

Fonte: elaborado pelas autoras a partir de dados da pesquisa (2020).

Dos 63 trabalhos analisados, 13 eram voltados aos docentes, discorrendo sobre a importância da leitura para a formação, suas trajetórias/histórias de leituras e se trabalhavam com textos além dos existentes nos livros didáticos em suas aulas. Do mesmo modo, desse total de trabalhos analisados, 4 eram sobre análise do ENPEC e investigaram a intertextualidade em textos de Ciências, a literatura e a Ciência, e a leitura e a Ciência. Havia alguns trabalhos que eram direcionados ao nível superior e discutiram sobre as experiências de leituras de licenciandos, análise de livros por estudantes do ensino superior, entre outros assuntos, totalizando 10 trabalhos.

Havia, ainda, 4 trabalhos que discutiam sobre textos do ENEM e leitura na disciplina de Ciências para pré-vestibulares. Sobre o lugar do texto de Ciências na composição do acervo bibliográfico das salas de leitura das escolas municipais do Rio de Janeiro, encontramos um trabalho que, mesmo não dialogando diretamente com o objetivo específico proposto para este texto, trouxe uma discussão interessante sobre a importância do acesso a essas obras. Encontramos 2 trabalhos que levantam reflexões sobre o que é Alfabetização Científica e outro que faz uma revisão de trabalhos que discutem leitura e Alfabetização Científica nas aulas de Ciências, publicados entre 2008 e 2012 .

Tabela 2. Foco dos trabalhos que possuíam a Educação Básica como contexto

\begin{tabular}{lc}
\hline \multicolumn{1}{c}{ Foco dos trabalhos } & Quantidade \\
\hline Alunos do ensino fundamental & 17 \\
Alunos do ensino médio & 11 \\
TOTAL & $\mathbf{2 8}$ \\
\hline
\end{tabular}

Fonte: elaborado pelas autoras a partir de dados da pesquisa (2020). 
Após retirarmos os trabalhos que não possuíam a Educação Básica como contexto, focamos a análise nos 28 trabalhos restantes e, destes, constatamos que 17 possuem como foco de análise alunos do ensino fundamental, sendo um deles sobre a modalidade de Educação de Jovens e Adultos (EJA). Concomitantemente, 11 trabalharam com o ensino médio, sendo um sobre a modalidade EJA, e 2 pesquisas que discorriam a respeito da importância da literatura infantil no ensino de Ciências, como explicitado na Figura 7.

Figura 7. Listagem dos trabalhos analisados, considerando edição do ENPEC, título do trabalho e categoria em que foi inserido

\begin{tabular}{|c|c|c|c|}
\hline $\begin{array}{l}\text { ENPEC/ } \\
\text { ANO }\end{array}$ & TÍTULO & CATEGORIA & REFERÊNCIA \\
\hline $\begin{array}{c}\text { III } \\
\text { ENPEC/ } \\
2001\end{array}$ & $\begin{array}{l}\text { Leitura e Compreensão } \\
\text { de Textos nos Livros } \\
\text { Didáticos de Ciências: } \\
\text { Um problema no } \\
\text { significado das palavras. }\end{array}$ & $\begin{array}{l}\text { Categoria 4: } \\
\text { A importância } \\
\text { da leitura para } \\
\text { a apropriação } \\
\text { da linguagem } \\
\text { científica. }\end{array}$ & $\begin{array}{l}\text { Ferraz et al. (2001). Leitura e } \\
\text { compreensão de textos nos livros } \\
\text { didáticos de ciências: um problema no } \\
\text { significado das palavras. III Encontro } \\
\text { Nacional de Pesquisa em Educação em } \\
\text { Ciências. }\end{array}$ \\
\hline $\begin{array}{c}\text { IV } \\
\text { ENPEC/ } \\
2003\end{array}$ & $\begin{array}{l}\text { Leitura no ensino de } \\
\text { ciências: a postura de } \\
\text { professores e alunos } \\
\text { perante o texto escrito. }\end{array}$ & $\begin{array}{l}\text { Categoria 2: } \\
\text { Estratégias de } \\
\text { Leitura. }\end{array}$ & $\begin{array}{l}\text { Gambarini e Bastos (2003). Leitura } \\
\text { no ensino de ciências: a postura de } \\
\text { professores e alunos perante o texto } \\
\text { escrito. IV Encontro Nacional de } \\
\text { Pesquisa em Educação em Ciências. }\end{array}$ \\
\hline $\begin{array}{c}\text { IV } \\
\text { ENPEC/ } \\
2003\end{array}$ & $\begin{array}{l}\text { Analogias e metáforas } \\
\text { no ensino de ciências: } \\
\text { análise da inserção de } \\
\text { um livro paradidático de } \\
\text { mecânica quântica e a } \\
\text { sua leitura por alunos do } \\
\text { ensino médio. }\end{array}$ & $\begin{array}{l}\text { Categoria 1: } \\
\text { Leitura como } \\
\text { construção social, } \\
\text { para além da } \\
\text { decodificação. }\end{array}$ & $\begin{array}{l}\text { Neves e Souza (2003). Analogias e } \\
\text { metáforas no ensino de ciências: análise } \\
\text { da inserção de um livro paradidático de } \\
\text { mecânica quântica e a sua leitura por } \\
\text { alunos do ensino médio. IV Encontro } \\
\text { Nacional de Pesquisa em Educação em } \\
\text { Ciências. }\end{array}$ \\
\hline $\begin{array}{c}\text { V } \\
\text { ENPEC/ } \\
2005\end{array}$ & $\begin{array}{l}\text { Mediações possíveis } \\
\text { numa leitura coletiva } \\
\text { para o ensino de ciências } \\
\text { e ambiente no ensino } \\
\text { fundamental. }\end{array}$ & $\begin{array}{l}\text { Categoria 1: } \\
\text { Leitura como } \\
\text { construção social, } \\
\text { para além da } \\
\text { decodificação. }\end{array}$ & $\begin{array}{l}\text { Giraldelli e Almeida (2005). Mediações } \\
\text { possíveis numa leitura coletiva para o } \\
\text { ensino de ciências e ambiente no ensino } \\
\text { fundamental. V Encontro Nacional de } \\
\text { Pesquisa em Educação em Ciências. }\end{array}$ \\
\hline $\begin{array}{c}\text { V } \\
\text { ENPEC/ } \\
2005\end{array}$ & $\begin{array}{l}\text { Textos no ensino- } \\
\text { aprendizagem de } \\
\text { ciências: primeiras } \\
\text { evidências a favor de } \\
\text { um modelo de trabalho } \\
\text { baseado em teorias de } \\
\text { leitura. }\end{array}$ & $\begin{array}{l}\text { Categoria 2: } \\
\text { Estratégias de } \\
\text { Leitura. }\end{array}$ & $\begin{array}{l}\text { Nigro e Trivelato (2005). Textos no } \\
\text { ensino-aprendizagem de ciências: } \\
\text { primeiras evidências a favor de um } \\
\text { modelo de trabalho baseado em teorias } \\
\text { de leitura. V Encontro Nacional de } \\
\text { Pesquisa em Educação em Ciências. }\end{array}$ \\
\hline $\begin{array}{c}\text { V } \\
\text { ENPEC/ } \\
2005\end{array}$ & $\begin{array}{l}\text { Concepções de ciência } \\
\text { na literatura infantil } \\
\text { brasileira: conhecer para } \\
\text { explorar possibilidades. }\end{array}$ & $\begin{array}{l}\text { Categoria 3: } \\
\text { A importância } \\
\text { do trabalho } \\
\text { com a leitura de } \\
\text { diferentes gêneros } \\
\text { textuais. }\end{array}$ & $\begin{array}{l}\text { Pinto e Raboni (2005). Concepções de } \\
\text { ciência na literatura infantil brasileira: } \\
\text { conhecer para explorar possibilidades. } \\
\text { V Encontro Nacional de Pesquisa em } \\
\text { Educação em Ciências. }\end{array}$ \\
\hline
\end{tabular}

Fonte: elaborado pelas autoras a partir de dados da pesquisa (2020). 
Figura 7. Listagem dos trabalhos analisados, considerando edição do ENPEC, título do trabalho e categoria em que foi inserido (continuação)

\begin{tabular}{|c|c|c|c|}
\hline $\begin{array}{l}\text { ENPEC/ } \\
\text { ANO }\end{array}$ & TÍTULO & CATEGORIA & REFERÊNCIA \\
\hline $\begin{array}{l}\text { VI } \\
\text { ENPEC/ } \\
2007\end{array}$ & $\begin{array}{l}\text { Leitura, discussão e } \\
\text { produção de textos como } \\
\text { recurso didático para o } \\
\text { letramento científico. }\end{array}$ & $\begin{array}{l}\text { Categoria 4: } \\
\text { A importância } \\
\text { da leitura para } \\
\text { a apropriação } \\
\text { da linguagem } \\
\text { científica. }\end{array}$ & $\begin{array}{l}\text { Soares e Coutinho (2007). Leitura, } \\
\text { discussão e produção de textos como } \\
\text { recurso didático para o letramento } \\
\text { científico. VI Encontro Nacional de } \\
\text { Pesquisa em Educação em Ciências. }\end{array}$ \\
\hline $\begin{array}{l}\text { VI } \\
\text { ENPEC/ } \\
2007\end{array}$ & $\begin{array}{l}\text { Uma avaliação da } \\
\text { aprendizagem de } \\
\text { conhecimentos associada } \\
\text { à leitura de textos de } \\
\text { ciências de diferentes } \\
\text { gêneros. }\end{array}$ & $\begin{array}{l}\text { Categoria 3: } \\
\text { A importância } \\
\text { do trabalho } \\
\text { com a leitura de } \\
\text { diferentes gêneros } \\
\text { textuais. } \\
\end{array}$ & $\begin{array}{l}\text { Nigro e Trivelato (2007). Uma avaliação } \\
\text { da aprendizagem de conhecimentos } \\
\text { associada à leitura de textos de ciências } \\
\text { de diferentes gêneros. VI Encontro } \\
\text { Nacional de Pesquisa em Educação em } \\
\text { Ciências. }\end{array}$ \\
\hline $\begin{array}{l}\text { VII } \\
\text { ENPEC/ } \\
2009\end{array}$ & $\begin{array}{l}\text { Leitura em aulas de } \\
\text { ciências: análise de } \\
\text { condições de produção. }\end{array}$ & $\begin{array}{l}\text { Categoria 1: } \\
\text { Leitura como } \\
\text { construção social, } \\
\text { para além da } \\
\text { decodificação. } \\
\end{array}$ & $\begin{array}{l}\text { Giraldi e Cassiani (2009). Leitura em } \\
\text { aulas de ciências: análise de condições } \\
\text { de produção. VII Encontro Nacional de } \\
\text { Pesquisa em Educação em Ciências. }\end{array}$ \\
\hline $\begin{array}{l}\text { VII } \\
\text { ENPEC/ } \\
2009\end{array}$ & $\begin{array}{l}\text { Histórias de leituras } \\
\text { de estudantes em aulas } \\
\text { de química no ensino } \\
\text { médio e as condições de } \\
\text { produção de sentidos. }\end{array}$ & $\begin{array}{l}\text { Categoria 3: } \\
\text { A importância } \\
\text { do trabalho } \\
\text { com a leitura de } \\
\text { diferentes gêneros } \\
\text { textuais. } \\
\end{array}$ & $\begin{array}{l}\text { Flor e Cassiani (2009). Histórias de } \\
\text { leituras de estudantes em aulas de } \\
\text { química no ensino médio e as condições } \\
\text { de produção de sentidos. VII Encontro } \\
\text { Nacional de Pesquisa em Educação em } \\
\text { Ciências. }\end{array}$ \\
\hline $\begin{array}{l}\text { VIII } \\
\text { ENPEC/ } \\
2011\end{array}$ & $\begin{array}{l}\text { Leituras e escritas de } \\
\text { estudantes do ensino } \\
\text { fundamental: entre a } \\
\text { paráfrase e a polissemia }\end{array}$ & $\begin{array}{l}\text { Categoria 1: } \\
\text { Leitura como } \\
\text { construção social, } \\
\text { para além da } \\
\text { decodificação. }\end{array}$ & $\begin{array}{l}\text { Giraldi e Cassiani (2011). Leituras } \\
\text { e escritas de estudantes do ensino } \\
\text { fundamental: entre a paráfrase e a } \\
\text { polissemia. VIII Encontro Nacional de } \\
\text { Pesquisa em Educação em Ciências. }\end{array}$ \\
\hline $\begin{array}{l}\text { VIII } \\
\text { ENPEC/ } \\
2011\end{array}$ & $\begin{array}{l}\text { Projeto leitura: uma } \\
\text { alternativa para a } \\
\text { percepção ambiental e o } \\
\text { ensino de ciências. }\end{array}$ & $\begin{array}{l}\text { Categoria 4: } \\
\text { A importância } \\
\text { da leitura para } \\
\text { a apropriação } \\
\text { da linguagem } \\
\text { científica. } \\
\end{array}$ & $\begin{array}{l}\text { Moreira et al. (2011). Projeto leitura: } \\
\text { uma alternativa para a percepção } \\
\text { ambiental e o ensino de ciências. VIII } \\
\text { Encontro Nacional de Pesquisa em } \\
\text { Educação em Ciências. }\end{array}$ \\
\hline $\begin{array}{l}\text { VIII } \\
\text { ENPEC/ } \\
2011\end{array}$ & $\begin{array}{l}\text { Significados } \\
\text { estabelecidos por alunos } \\
\text { da quinta série, a partir } \\
\text { da leitura de texto e } \\
\text { figura representativa de } \\
\text { fotossíntese, utilizada } \\
\text { durante atividade de } \\
\text { investigação. }\end{array}$ & $\begin{array}{l}\text { Categoria 2: } \\
\text { Estratégias de } \\
\text { Leitura. }\end{array}$ & $\begin{array}{l}\text { Zômpero e Laburú (2001). Significados } \\
\text { estabelecidos por alunos da quinta } \\
\text { série, a partir da leitura de texto e figura } \\
\text { representativa de fotossíntese, utilizada } \\
\text { durante atividade de investigação. VIII } \\
\text { Encontro Nacional de Pesquisa em } \\
\text { Educação em Ciências. }\end{array}$ \\
\hline
\end{tabular}

Fonte: elaborado pelas autoras a partir de dados da pesquisa (2020). 
Figura 7. Listagem dos trabalhos analisados, considerando edição do ENPEC, título do trabalho e categoria em que foi inserido (continuação)

\begin{tabular}{|c|c|c|c|}
\hline $\begin{array}{c}\text { ENPEC/ } \\
\text { ANO }\end{array}$ & TÍTULO & CATEGORIA & REFERÊNCIA \\
\hline $\begin{array}{c}\text { IX } \\
\text { ENPEC/ } \\
2013\end{array}$ & $\begin{array}{l}\text { Uma leitura de } \\
\text { divulgação científica } \\
\text { sobre ressonância } \\
\text { magnética no ensino } \\
\text { médio. }\end{array}$ & $\begin{array}{l}\text { Categoria 4: } \\
\text { A importância } \\
\text { da leitura para } \\
\text { a apropriação } \\
\text { da linguagem } \\
\text { científica. }\end{array}$ & $\begin{array}{l}\text { Silva e Almeida (2013). Maria José } \\
\text { Pereira Monteiro de. Uma leitura de } \\
\text { divulgação científica sobre ressonância } \\
\text { magnética no ensino médio. IX } \\
\text { Encontro Nacional de Pesquisa em } \\
\text { Educação em Ciências. }\end{array}$ \\
\hline $\begin{array}{c}\text { IX } \\
\text { ENPEC/ } \\
2013\end{array}$ & $\begin{array}{l}\text { O pisa: leituras de } \\
\text { ciências e tecnologias no } \\
\text { ensino fundamental. }\end{array}$ & $\begin{array}{l}\text { Categoria 2: } \\
\text { Estratégias de } \\
\text { Leitura. }\end{array}$ & $\begin{array}{l}\text { Simas et al. (2013). O pisa: leituras } \\
\text { de ciências e tecnologias no ensino } \\
\text { fundamental. IX Encontro Nacional de } \\
\text { Pesquisa em Educação em Ciências. }\end{array}$ \\
\hline $\begin{array}{c}\text { IX } \\
\text { ENPEC/ } \\
2013\end{array}$ & $\begin{array}{l}\text { Percepções de alunos } \\
\text { do ensino médio sobre } \\
\text { o livro didático de } \\
\text { química. }\end{array}$ & $\begin{array}{l}\text { Categoria 3: } \\
\text { A importância } \\
\text { do trabalho } \\
\text { com a leitura de } \\
\text { diferentes gêneros } \\
\text { textuais. }\end{array}$ & $\begin{array}{l}\text { Sillos e Santos (2013). Percepções de } \\
\text { alunos do ensino médio sobre o livro } \\
\text { didático de química. IX Encontro } \\
\text { Nacional de Pesquisa em Educação em } \\
\text { Ciências. }\end{array}$ \\
\hline $\begin{array}{l}\text { IX } \\
\text { ENPEC/ } \\
2013\end{array}$ & $\begin{array}{l}\text { Leitura em uma sala } \\
\text { de aula de ciências: a } \\
\text { construção social de } \\
\text { conexões intertextuais } \\
\text { em uma unidade didática } \\
\text { de ecologia. } \\
\end{array}$ & $\begin{array}{l}\text { Categoria 1: } \\
\text { Leitura como } \\
\text { construção social, } \\
\text { para além da } \\
\text { decodificação. }\end{array}$ & $\begin{array}{l}\text { Ribeiro e Munford (2013). Leitura } \\
\text { em uma sala de aula de ciências: } \\
\text { a construção social de conexões } \\
\text { intertextuais em uma unidade didática } \\
\text { de ecologia. IX Encontro Nacional de } \\
\text { Pesquisa em Educação em Ciências. }\end{array}$ \\
\hline $\begin{array}{l}\text { IX } \\
\text { ENPEC/ } \\
2013\end{array}$ & $\begin{array}{l}\text { As contribuições de } \\
\text { uma estratégia de leitura } \\
\text { em uma perspectiva } \\
\text { progressista para a } \\
\text { educação química. }\end{array}$ & $\begin{array}{l}\text { Categoria 2: } \\
\text { Estratégias de } \\
\text { Leitura. }\end{array}$ & $\begin{array}{l}\text { Guaita e Gonçalves (2013). As } \\
\text { contribuições de uma estratégia de } \\
\text { leitura em uma perspectiva progressista } \\
\text { para a educação química. IX Encontro } \\
\text { Nacional de Pesquisa em Educação em } \\
\text { Ciências. }\end{array}$ \\
\hline $\begin{array}{c}\mathrm{X} \\
\text { ENPEC/ } \\
2015\end{array}$ & $\begin{array}{l}\text { Sentidos produzidos por } \\
\text { estudantes do ensino } \\
\text { médio na leitura de um } \\
\text { texto de cientista do } \\
\text { início da física quântica. }\end{array}$ & $\begin{array}{l}\text { Categoria 1: } \\
\text { Leitura como } \\
\text { construção social, } \\
\text { para além da } \\
\text { decodificação. }\end{array}$ & $\begin{array}{l}\text { Pagliarini e Almeida (2015). Sentidos } \\
\text { produzidos por estudantes do ensino } \\
\text { médio na leitura de um texto de cientista } \\
\text { do início da física quântica. X Encontro } \\
\text { Nacional de Pesquisa em Educação em } \\
\text { Ciências. }\end{array}$ \\
\hline $\begin{array}{c}\mathrm{X} \\
\text { ENPEC/ } \\
2015\end{array}$ & $\begin{array}{l}\text { A literatura infantil } \\
\text { no ensino de ciências: } \\
\text { possibilidades para } \\
\text { formação leitora. }\end{array}$ & $\begin{array}{l}\text { Categoria 1: } \\
\text { Leitura como } \\
\text { construção social, } \\
\text { para além da } \\
\text { decodificação. }\end{array}$ & $\begin{array}{l}\text { Miranda et al. (2015). A literatura } \\
\text { infantil no ensino de ciências: } \\
\text { possibilidades para formação leitora. } \\
\text { X Encontro Nacional de Pesquisa em } \\
\text { Educação em Ciências. }\end{array}$ \\
\hline
\end{tabular}

Fonte: elaborado pelas autoras a partir de dados da pesquisa (2020). 
Figura 7. Listagem dos trabalhos analisados, considerando edição do ENPEC, título do trabalho e categoria em que foi inserido (continuação)

\begin{tabular}{|c|c|c|c|}
\hline $\begin{array}{c}\text { ENPEC/ } \\
\text { ANO }\end{array}$ & TÍTULO & CATEGORIA & REFERÊNCIA \\
\hline $\begin{array}{c}\text { X } \\
\text { ENPEC/ } \\
2015\end{array}$ & $\begin{array}{l}\text { Ler e compreender nas } \\
\text { aulas de ciências: uma } \\
\text { análise. }\end{array}$ & $\begin{array}{l}\text { Categoria 1: } \\
\text { Leitura como } \\
\text { construção social, } \\
\text { para além da } \\
\text { decodificação. } \\
\end{array}$ & $\begin{array}{l}\text { Sedano e Carvalho (2015). Ler e } \\
\text { compreender nas aulas de ciências: } \\
\text { uma análise. X Encontro Nacional de } \\
\text { Pesquisa em Educação em Ciências. }\end{array}$ \\
\hline $\begin{array}{c}\text { X } \\
\text { ENPEC/ } \\
2015\end{array}$ & $\begin{array}{l}\text { O ensino de biologia e a } \\
\text { leitura em sala de aula. }\end{array}$ & $\begin{array}{l}\text { Categoria 2: } \\
\text { Estratégias de } \\
\text { Leitura. }\end{array}$ & $\begin{array}{l}\text { Araújo e Carneiro (2015). O ensino de } \\
\text { biologia e a leitura em sala de aula. X } \\
\text { Encontro Nacional de Pesquisa em } \\
\text { Educação em Ciências. }\end{array}$ \\
\hline $\begin{array}{c}\text { X } \\
\text { ENPEC/ } \\
2015\end{array}$ & $\begin{array}{l}\text { Textos multimodais } \\
\text { no ensino de biologia: } \\
\text { entendendo a leitura dos } \\
\text { alunos. }\end{array}$ & $\begin{array}{l}\text { Categoria 2: } \\
\text { Estratégias de } \\
\text { Leitura. }\end{array}$ & $\begin{array}{l}\text { Freitas e Rocha (2015). Textos } \\
\text { multimodais no ensino de biologia: } \\
\text { entendendo a leitura dos alunos. X } \\
\text { Encontro Nacional de Pesquisa em } \\
\text { Educação em Ciências. }\end{array}$ \\
\hline $\begin{array}{c}\text { X } \\
\text { ENPEC/ } \\
2015\end{array}$ & $\begin{array}{l}\text { Clube do livro científico: } \\
\text { aproximações entre } \\
\text { ciência e literatura na } \\
\text { escola. }\end{array}$ & \begin{tabular}{|l|} 
Categoria 1: \\
Leitura como \\
construção social, \\
para além da \\
decodificação. \\
\end{tabular} & $\begin{array}{l}\text { Ramos et al. (2015). Clube do livro } \\
\text { científico: aproximações entre ciência } \\
\text { e literatura na escola. X Encontro } \\
\text { Nacional de Pesquisa em Educação em } \\
\text { Ciências. }\end{array}$ \\
\hline $\begin{array}{c}\mathrm{X} \\
\text { ENPEC/ } \\
2015\end{array}$ & $\begin{array}{l}\text { Leitura de textos de } \\
\text { não ficção em aulas de } \\
\text { ciências: explorando a } \\
\text { diversidade de formas de } \\
\text { engajamento. }\end{array}$ & $\begin{array}{l}\text { Categoria 3: } \\
\text { A importância } \\
\text { do trabalho } \\
\text { com a leitura de } \\
\text { diferentes gêneros } \\
\text { textuais. }\end{array}$ & $\begin{array}{l}\text { Meireles et al. (2015). Leitura de textos } \\
\text { de não ficção em aulas de ciências: } \\
\text { explorando a diversidade de formas de } \\
\text { engajamento. X Encontro Nacional de } \\
\text { Pesquisa em Educação em Ciências. }\end{array}$ \\
\hline $\begin{array}{l}\text { XI } \\
\text { ENPEC/ } \\
2017\end{array}$ & $\begin{array}{l}\text { Atividades de leitura } \\
\text { e escrita em aulas de } \\
\text { ciências: reflexões } \\
\text { sobre linguagem e } \\
\text { conhecimento escolar. }\end{array}$ & $\begin{array}{l}\text { Categoria 2: } \\
\text { Estratégias de } \\
\text { Leitura. }\end{array}$ & $\begin{array}{l}\text { Matos (2017). Atividades de leitura e } \\
\text { escrita em aulas de ciências: reflexões } \\
\text { sobre linguagem e conhecimento escolar. } \\
\text { XI Encontro Nacional de Pesquisa em } \\
\text { Educação em Ciências. }\end{array}$ \\
\hline $\begin{array}{l}\text { XI } \\
\text { ENPEC/ } \\
2017\end{array}$ & $\begin{array}{l}\text { Avaliação da } \\
\text { compreensão de leitura } \\
\text { de textos científicos na } \\
\text { educação de jovens e } \\
\text { adultos - EJA. }\end{array}$ & $\begin{array}{l}\text { Categoria 4: } \\
\text { A importância } \\
\text { da leitura para } \\
\text { a apropriação } \\
\text { da linguagem } \\
\text { científica. } \\
\end{array}$ & $\begin{array}{l}\text { Araújo e Carneiro (2017). Avaliação } \\
\text { da compreensão de leitura de textos } \\
\text { científicos na educação de jovens e } \\
\text { adultos - EJA. XI Encontro Nacional } \\
\text { de Pesquisa em Educação em } \\
\text { Ciências. }\end{array}$ \\
\hline $\begin{array}{l}\text { XI } \\
\text { ENPEC/ } \\
2017\end{array}$ & $\begin{array}{l}\text { Prática de leitura } \\
\text { em uma aula de } \\
\text { química: literatura e } \\
\text { experimentação. }\end{array}$ & $\begin{array}{l}\text { Categoria 3: } \\
\text { A importância } \\
\text { do trabalho } \\
\text { com a leitura de } \\
\text { diferentes gêneros } \\
\text { textuais. }\end{array}$ & $\begin{array}{l}\text { Targino e Giordan (2017). Prática } \\
\text { de leitura em uma aula de química: } \\
\text { literatura e experimentação. XI } \\
\text { Encontro Nacional de Pesquisa em } \\
\text { Educação em Ciências. }\end{array}$ \\
\hline
\end{tabular}

Fonte: elaborado pelas autoras a partir de dados da pesquisa (2020). 


\section{As singularidades identificadas entre os trabalhos apresentados no ENPEC: o que se pesquisa sobre leitura e ensino de Ciências na Educação Básica}

Os trabalhos que possuem como contexto a Educação Básica apontam para diversas discussões importantes e necessárias no debate sobre leitura e ensino de Ciências. Algumas pesquisas destacam a importância do trabalho com a leitura em todas as disciplinas, sem haver segregação entre leitura e ensino de Ciências, compactuando, assim, com o que a literatura das áreas de Educação e de Ensino tem indicado: o compromisso do ensino e o trabalho com a leitura em todas as áreas de conhecimento.

Também é perceptível a defesa de uma proposta didática que possua um olhar mais atento ao se trabalhar leitura nas aulas de Ciências, pensando em estratégias capazes de promover a compreensão leitora e a Alfabetização Científica. Concomitantemente, os trabalhos também tecem a discussão sobre a necessidade do trabalho com os diversos gêneros textuais nas aulas, bem como a discussão sobre a leitura como ferramenta indispensável para que os alunos se apropriem da linguagem científica.

Nesse contexto teórico, em observância aos dados que emergiram nesta pesquisa, e de acordo com o objetivo de investigação traçado, apresentaremos a seguir as categorias de análise. Assim, a partir dos trabalhos referentes à Educação Básica e, para aclararmos e aprofundarmos a análise, serão considerados dois trabalhos em cada categoria.

\section{Categoria 1: Leitura como construção social, para além da decodificação}

Alguns trabalhos apresentam uma discussão sobre a importância da leitura, abordando-a como uma construção social, para além do processo de decodificação e/ou como um processo cognitivo de construção de sentidos. Quando entendemos a leitura como uma construção social, adotamos a ideia da interação do leitor com o texto e, nesse aspecto, a importância dos conhecimentos prévios do leitor. $\mathrm{O}$ leitor não chega "vazio" para ler o texto. Ele vem carregado com seus conhecimentos prévios e o ato de ler é uma interação do leitor com seus conhecimentos prévios e o texto (Cafiero, 2005; Kleiman, 2004; Solé 1996).

Entre os aspectos discutidos nos trabalhos analisados, destacam-se: a linguagem metafórica como um dos recursos para se ensinar Ciências; a mediação do professor no processo de leitura; o uso da intertextualidade na sala de aula; literatura como mediadora no ensino de Ciências, além de proporem mudanças na prática de abordagem da leitura e escrita em aulas de Ciências (Giraldelli \& Almeida, 2005; Giraldi \& Cassiani, 2009; Giraldi \& Cassiani, 2011; Miranda et al., 2015; Neves \& Souza, 2003; Pagliarini \& Almeida, 2015; Ramos et al., 2015; Ribeiro \& Munford, 2013; Sedano \& Carvalho, 2015).

O trabalho de Giraldelli e Almeida (2005) discute a importância da leitura coletiva de um texto de literatura infantil e a interação dos alunos ( 29 crianças de nove a 10 anos de idade) de uma escola pública estadual de Campinas, por meio do texto "Tem um cabelo na minha terra!" em que foram distribuídos 14 livros, um para cada duas crianças, e a leitura foi conduzida principalmente por uma das pesquisadoras, sendo toda a atividade gravada. As pesquisadoras analisaram os diálogos que aconteceram 
durante e após a leitura para compreender o funcionamento e a contribuição da leitura coletiva. Esse exame foi feito baseado na análise de discurso de linha francesa, em que a autora traz a questão da interpretação como relação entre ideologia e inconsciente, tendo como meio material a linguagem.

A pesquisa de Giraldelli e Almeida (2005) explicita, ainda, o importante papel da literatura como mediadora no ensino de Ciências. As autoras apontam a leitura como fundamental no processo de construção do conhecimento científico, afirmando que, em sala de aula, o funcionamento de textos precisa ser compreendido no âmbito das interações que ali ocorrem, pois estão em jogo concepções e representações de Ciência, de leitura e de ensino, além das expectativas mútuas que condicionam os sujeitos no processo. Nesse sentido, Cafiero (2005) afirma: "nas aulas de leitura, o aluno precisa aprender a lidar com a leitura como um processo. Para isso, ele precisa realizar atividades que o ajudem a tornar-se consciente de algumas estratégias e aprender a monitorar seu próprio processo e ao mesmo tempo precisa ver a leitura como processo de interação" (p. 48).

Giraldelli e Almeida (2005) discorrem que a atividade com a leitura possibilitou a interação entre os alunos por meio de um texto que trouxe uma construção de conceitos para as crianças e possibilitou reflexões de natureza ecológica, no sentido de conhecer e julgar a própria realidade.

Nessa categoria também foi encontrado o trabalho de Ramos et al. (2015) que analisaram os resultados de uma atividade em que o livro "O Guia do Mochileiro das Galáxias" foi utilizado como material didático, os estudantes de $8^{\circ}$ e $9^{\circ}$ ano do Ensino Fundamental II leram trechos da obra e discutiram sobre o que seria necessário para "mochilar" pelo universo. Os autores afirmam que a leitura foi capaz de fazer com que os alunos identificassem conceitos científicos na obra, além de proporcionar um diálogo com o livro. Ao longo do trabalho, os autores propuseram uma discussão acerca da necessidade de se trabalhar a leitura no ensino de Ciências e destacaram a importância das atividades não formais que acabam por incentivar a leitura por prazer. Por isso, a leitura em aulas de Ciências deve possuir objetivos que vão além da decodificação:

Assim, encontramos um paradoxo que, enquanto fora da escola o estudante é perfeitamente capaz de planejar as ações que o levarão a um objetivo predeterminado (por exemplo, elogiar alguém para conseguir um favor), quando se trata de leitura, de interação a distância mediante o texto, a maioria das vezes esse estudante começa a ler sem ter ideia de onde quer chegar [...] (Kleiman, 2004, p. 30).

Sendo assim, as práticas de leitura em sala de aula devem proporcionar aos alunos o prazer em ler e, ao mesmo tempo, possibilitar a construção de significados. Assim, os alunos compreenderão o que estão lendo, para que estão lendo e quais objetivos desejam com a leitura (Evangelista \& Jerônimo, 2014). 


\section{Categoria 2: Estratégias de Leitura}

Nessa categoria estão os trabalhos que, além de apresentarem a discussão acerca da leitura como um processo que transcende a decodificação, também discutem a importância de desenvolver algumas estratégias de leitura em aulas de Ciências (Coscarelli, 2002; Solé, 1996).

Dentre os aspectos discutidos nesses trabalhos, destacam-se: a elaboração de modelos para abordar textos pragmáticos usados no ensino e aprendizagem de Ciências, considerando teorias de leitura; uso de cartilhas informativas como estratégias de ensino que possibilitem transformar a leitura em uma prática comum em todas as disciplinas da matriz curricular do ensino fundamental; interpretação e condições de produção de sentido; dificuldade dos alunos em ler e interpretar textos multimodais; transformações da linguagem que podem ocorrer a partir de atividades de leitura e escrita em aulas de Ciências.

Além disso, esses estudos discutem o quão necessário é desfazer a crença generalizada de que o único professor a trabalhar com leitura e escrita deva ser o de língua materna, acrescentando que todos os docentes são professores de leitura (Araújo \& Carneiro, 2015; Freitas \& Rocha, 2015; Nigro \& Trivelato, 2005; Gambarini \& Bastos, 2003; Guaita \& Gonçalves, 2013; Matos, 2017; Simas et al., 2013; Zômpero \& Laburú, 2011).

O trabalho de Guaita e Gonçalves (2013) descreve uma estratégia em que atividades de leitura foram propostas em uma turma do $2^{\circ}$ ano do ensino médio, a fim de saber as interpretações que os alunos faziam para que pudessem ser problematizadas posteriormente, e as informações qualitativas obtidas foram submetidas aos procedimentos da análise textual discursiva. Com isso, o estudo comprovou que a estratégia de leitura contribuiu para mapear os conhecimentos dos discentes sobre os assuntos estudados e para favorecer a evolução destes conhecimentos, na medida em que o ato de ler transcende a descrição e memorização, por exemplo.

Segundo Solé (1996), para o desenvolvimento da leitura proficiente, as estratégias de leitura são essenciais. A autora declara: "poder ler, isto é, compreender e interpretar textos escritos de diversos tipos com diferentes intenções e objetivos contribui de forma decisiva para a autonomia das pessoas, na medida em que a leitura é um instrumento necessário para que nos manejemos com certas garantias de uma sociedade letrada" (p. 18).

Por isso, Guaita e Gonçalves (2013) apontam a importância da leitura e do uso de estratégias para o trabalho com ela na educação química. Os autores declaram ainda que todos os docentes, independentemente de suas áreas de formação, são professores de leitura.

Ainda discutindo estratégias de leitura, Freitas e Rocha (2015) realizaram uma análise para compreenderem como estudantes do ensino médio leem materiais didáticos multimodais. O objetivo era ensinar Biologia e produzir material didático. Cada uma das turmas tinha cerca de 30 alunos que foram organizados em 10 grupos de três 
pessoas, e foram produzidos textos a partir da leitura do material impresso. Os autores analisaram os textos para compreender como usaram a linguagem e a interpretaram. Foi evidenciado que há uma dificuldade por parte dos alunos em ler e interpretar textos multimodais. Os autores concluíram que é fundamental que os professores de Ciências leiam as imagens e os textos multimodais com seus alunos.

Solé (1996), ao discutir o que é uma estratégia, discorre que um componente essencial das estratégias é a autodireção. A autora declara que deve existir um objetivo e a consciência de sua existência. Assim, existirá, também, a supervisão e avaliação do comportamento da própria pessoa para atingir esse objetivo. Para a autora, estratégias de compreensão leitora também seguem esse raciocínio, ou seja, devem possuir objetivos, planejamentos de ações, avaliações e possíveis mudanças a fim de cumprir o objetivo proposto.

\section{Categoria 3: A importância do trabalho com a leitura de diferentes gêneros textuais}

Nesta categoria, incluímos os trabalhos que abordaram a necessidade de se trabalhar com diversos gêneros textuais em aulas de Ciências (Coscarelli, 2002; Solé, 1996; Pereira \& Lima, 2018).

Entre os aspectos discutidos nesses trabalhos, destacam-se: a problematização do uso do livro didático; erros conceituais e concepções equivocadas de Ciência e de cientista presentes na literatura infantil; uso de gêneros textuais como influenciadores da aprendizagem a partir da leitura; uso do texto literário de divulgação científica em aulas de Ciências; discussão sobre a formação de leitores no contexto da Educação Científica (Flor \& Cassiani, 2009; Meireles et al., 2015; Nigro \& Trivelato, 2007; Pinto \& Raboni, 2005; Sillos \& Santos, 2013; Targino \& Giordan, 2017).

Nigro e Trivelato (2007) discutem sobre os textos usados no ensino-aprendizagem de Ciências e a relação deles com a compreensão leitora dos estudantes na faixa etária de 14 e 15 anos de uma escola particular localizada na cidade de São Paulo. Foram feitos testes de aplicação de conhecimentos associados à leitura dos textos, aplicação e análise estatística. Os autores concluem que os diferentes gêneros de textos e a diferença de gênero dos estudantes são fatores que podem influenciar na aprendizagem a partir da leitura. E afirmam que o estudo ratifica o quanto a leitura na educação em Ciências não é algo trivial, tratando-se de um tema que merece ser objeto de investigações mais profundas, dada a sua complexidade e relevância para a promoção da Alfabetização Científica em seu sentido mais fundamental.

Sobre isso, Coscarelli (2002) aponta a importância do trabalho com diferentes gêneros textuais para que o leitor compreenda o que lê. Segundo ela, o leitor que não conhece bem o gênero textual que está lendo, provavelmente, terá problemas para a compreensão dele, pois "se o leitor conhece o gênero textual, sabe o que deve esperar de cada parte dele e pode, inclusive, desenvolver estratégias para a sua leitura" (p. 23). 
Do mesmo modo, Solé (1996) discorre que quando ensinamos os alunos a lerem diferentes tipos de textos, também estamos ensinando que em alguns deles, como os expositivos em suas diferentes modalidades, a leitura é quem irá ajudá-los a entender e oferecer novas informações sobre o tema.

Outro trabalho incluído nesta categoria que sinaliza a importância do trabalho com diversos gêneros textuais é o de Meireles et al. (2015). As autoras discutiram como crianças dos três primeiros anos do ensino fundamental podem se engajar de diversos modos na leitura de textos de não ficção em sala de aula. Para isso, elas realizaram a observação participante ao longo dos três anos do primeiro ciclo e produziram registros em caderno de campo, em vídeo e áudio das aulas, e coletaram artefatos produzidos em sala de aula, a fim de compreender o processo de escolarização da turma. A pesquisa demonstra que estudos como esses possibilitam explorar outras relações entre leitura e aprendizagem de Ciências e evidenciam a importância de uma prática aliando leitura e ensino de Ciências.

Sobre isso, Pereira e Lima (2018) apontam a necessidade de "os professores, de todas as áreas de ensino, realizem práticas leitoras de diferentes gêneros textuais em suas aulas diárias, pois formar leitores críticos e ativos, é um processo coletivo" (p. 34). Segundo os autores, as práticas de leitura no ensino de Ciências devem envolver diversos gêneros textuais aliados às estratégias de leitura, pois isso possibilitará ao estudante realizar associações e reflexões do tema abordado no texto com questões científicas, tecnológicas e sociais.

\section{Categoria 4: A importância da leitura para a apropriação da linguagem científica}

Nesta categoria, agrupamos os trabalhos que discutem a importância da leitura para a apropriação da linguagem científica, compreendendo-a como necessária por ser um componente básico da educação e da busca constante de conhecimento (Mortimer, 1998; Wenzel, 2017).

Entre os aspectos discutidos nesses trabalhos, destacam-se: o que é Letramento Científico; a importância de trabalhar textos de divulgação científica nas aulas; falta de domínio dos estudantes em reconhecer/utilizar o vocabulário da área de Ciências; linguagem empregada nos textos didáticos utilizados por alunos da educação básica (Soares \& Coutinho, 2007; Silva \& Almeida, 2013; Araújo \& Carneiro, 2017; Ferraz et al., 2001).

O trabalho de Ferraz et al. (2001) discute acerca da linguagem empregada nos textos didáticos utilizados por alunos do ensino fundamental, indicando dificuldades de domínio vocabular. Os autores utilizaram um texto didático da área de Ciências Biológicas, especificamente, Animais Peçonhentos, extraído do livro didático "Ciência em Nova Dimensão", de autoria de Odair Carvalho e Napoleão Fernandes (1996), que foi lido por alunos de $6^{\mathrm{a}}$ e $8^{\mathrm{a}}$ séries do ensino fundamental. Após a leitura, os alunos destacaram as palavras cujo significado desconheciam. 
Os autores apontam que a análise dos dados revelou que a seriação dos estudantes pouco contribuiu para o entendimento de termos novos tanto da Língua Portuguesa quanto do conteúdo de Ciências Biológicas. Destacam ainda a desatenção dos alunos para termos, cujo significado é explicitado pelo autor no próprio texto, sugerindo dificuldades no processo de leitura. $O$ estudo também aponta o professor como sujeito fundamental para mediar o processo de leitura. Os autores ressaltam a grande importância de as Ciências e a Língua Portuguesa trabalharem juntas para proporcionar um melhor aproveitamento dos alunos em ambas as disciplinas.

Sobre isso, Mortimer et al. (1998) discutem que, por possuir características próprias que a distinguem da linguagem comum, a linguagem científica torna-se estranha e difícil para os alunos. Diante disso, os autores afirmam que "reconhecer essas diferenças implica admitir que a aprendizagem da ciência é inseparável da aprendizagem da linguagem científica" (Mortimer et al., 1998, p. 08). Disso deriva a importância e necessidade do trabalho com textos em aulas de Ciências.

Outro trabalho incluído nesta categoria que destaca a importância da leitura para apropriação da linguagem científica é o de Silva e Almeida (2013). Os autores discorrem sobre uma determinada experiência de leitura. Após um texto de divulgação científica sobre ressonância magnética ter sido trabalhado em três turmas do segundo ano do ensino médio de uma escola pública da cidade de Campinas-SP, os autores realizaram uma análise das considerações feitas pelos alunos. Apoiados em noções apresentadas por Eni Orlandi no escopo da Análise de Discurso em sua vertente iniciada na França por Michel Pêcheux, os autores objetivaram compreender o funcionamento da leitura de divulgação científica no que diz respeito à produção de sentidos por parte dos estudantes. Desse modo, os autores ainda salientam a importância de se trabalhar textos de divulgação científica e a necessidade da leitura em aulas de física.

Por isso, Wenzel (2017) defende a urgência de ampliação dos espaços do uso da linguagem científica escolar pelos estudantes, seja por meio da escrita, leitura ou outros instrumentos. Segundo o autor, ao internalizar a linguagem específica da Ciência, o estudante "proporciona a evolução dos significados atribuídos e será capaz de operá-los em diferentes situações, realizando as necessárias relações conceituais” (Wenzel, 2017, p. 20).

\section{Considerações Finais}

Discutir a presença da leitura no ensino de Ciências é imprescindível, seja pelo papel estruturante que ela possui na sociedade ou pela indiscutível importância na promoção da Alfabetização Científica. Neste estudo, compreendemos de que forma as discussões sobre leitura e ensino de Ciências estão sendo apresentadas nos trabalhos publicados sobre a temática do ENPEC, considerando as edições de 1997 a 2019. Além disso, entendemos que este artigo traz uma contribuição para a área, tendo em vista que apresenta um panorama das pesquisas sobre o trabalho com leitura e ensino de Ciências até o momento. 
Centramos a nossa investigação nos trabalhos que se propuseram a pesquisar a temática na Educação Básica. Alinhadas com as publicações da área, entendemos que são nas diferentes etapas desse momento formativo que o estudante terá a oportunidade de aprender a ler, desde suas primeiras experimentações e vivências de letramento na Educação Infantil, até as leituras com enfoque problematizador, de diferentes gêneros textuais e objetivando, cada vez mais, inferências aprofundadas no ensino médio.

Nossa investigação demonstrou a carência por mais pesquisas sobre leitura e ensino de Ciências no ENPEC. A análise denota que as tendências dos trabalhos encontrados direcionam para diversos debates pertinentes como: o uso exclusivo do livro didático como único suporte para a atividade de leitura; a importância de desenvolver estratégias de leitura no ensino de Ciências e a necessidade de se trabalhar com diversos gêneros textuais nas aulas. Concomitantemente, os trabalhos também apresentam uma discussão acerca da inquestionável importância da leitura no processo da Alfabetização e Letramento Científico, denunciando a enorme segregação entre leitura e ensino de Ciências.

Foi possível obtermos um panorama das investigações realizadas, bem como destacarmos os principais aspectos abordados nesses trabalhos. Compreender como a leitura está sendo relacionada ao ensino de Ciências em discussões de eventos de referência na área de Ciências, como o ENPEC, é fundamental, uma vez que são eventos que favorecem a interação entre os pesquisadores das áreas, que têm a possibilidade de discutir temas fundamentais para pensarmos a Educação Científica.

Por isso, é importante destacar a imprescindibilidade de mais produções que fomentem as discussões sobre a relevância do trabalho com a leitura em todas as áreas do conhecimento, inclusive no ensino de Ciências, tendo em vista que esta pesquisa aponta a relevância da leitura para a Educação Básica, nível de ensino que ainda apresenta muitas fragilidades no trabalho com a leitura e, também, no ensino de Ciências.

Como perspectiva para pesquisas futuras, destacamos a importância de uma investigação sobre qual o papel que a leitura está ocupando nas discussões presentes na formação inicial e continuada de professores de Ciências, já que os trabalhos analisados apontam o professor como figura essencial na mediação entre a leitura e o ensino de Ciências. Pretendemos investigar, também, aspectos mais específicos da compreensão leitora e como ela pode ser mais bem desenvolvida nas aulas de Ciências que objetivam promover a Alfabetização Científica.

\section{Agradecimentos}

À Coordenação de Aperfeiçoamento de Pessoal de Nível Superior - CAPES. Aos avaliadores deste artigo pelas importantes contribuições no avanço deste estudo. 


\section{Referências}

Almeida, S. A. D. (2018). Cenas de leitura da ciência hoje das crianças: modos de uso e apropriação da revista em sala de aula. Educação em Revista, (34), 1-28. https://doi. org/10.1590/0102-4698173829

Andrade, I. B., \& Martins, I. (2006). Discursos de Professores de Ciências Sobre Leitura. Investigações em Ensino de Ciências, 11(2), 121-151.

Andrade, I. B., Rocha, M. A., Vermelho, S. C., \& Martins, I. (24-27 de novembro, 2015). Uma análise dos trabalhos apresentados no ENPEC sobre Leitura e Educação em Ciências. X Encontro Nacional de Pesquisa em Educação em Ciências (ENPEC), Águas de Lindóia, São Paulo.

Araújo, M., Bekman, L., Silva, J., \& Barroso, R. R. (03-06 de julho, 2017). Abordagem da leitura no ensino de ciências: um estudo a partir das pesquisas produzidas nos Encontros Nacionais de Pesquisas em Educação em Ciências (ENPEC's) - 2005 a 2015. XI Encontro Nacional de Pesquisa em Educação em Ciências (ENPEC), Florianópolis, Santa Catarina.

Araújo, S. P., \& Carneiro, M. H. S. (03-06 de julho, 2017). Avaliação da compreensão de leitura de textos científicos na educação de jovens e adultos - EJA. XI Encontro Nacional de Pesquisa em Educação em Ciências (ENPEC), Florianópolis, Santa Catarina.

Araújo, S. P., \& Carneiro, M. H. S. (24-27 de novembro, 2015). O ensino de biologia e a leitura em sala de aula. X Encontro Nacional de Pesquisa em Educação em Ciências (ENPEC), Águas de Lindóia, São Paulo.

Ardasheva, Y., Norton-Meier, L., \& Hand, B. (2015). Negotiation, embeddedness, and non-threatening learning environments as themes of science and language convergence for English language learners. Studies in Science Education, 51(2), 201-249. https://doi. org/10.1080/03057267.2015.1078019

Ariely, M., Livnat, Z., \& Yarden, A. (2019). Analyzing the Language of an Adapted Primary Literature Article. Science \& Education, 28(4), 63-85. http://dx.doi.org/10.1007/ s11191-019-00033-5

Azevedo, N. H., \& Scarpa, D. L. (2017). Revisão sistemática de trabalhos sobre concepções de natureza da ciência no ensino de ciências. Revista Brasileira de Pesquisa em Educação em Ciências, 17(2), 579-619. https://doi.org/10.28976/1984-2686rbpec2017172579

Bardin, L. (2009). Análise de conteúdo. Edições 70.

Bratkovich, M. O. (2018). Shining Light on Language for, in, and as Science Content. Science \& Education, 27(4), 769-782. https://doi.org/10.1007/s11191-018-9998-3

Bueno, O. O., \& Luz, G. L. M. (2014). A leitura nas séries iniciais: alguns elementos metodológicos no processo ensino-aprendizagem. Revista Eventos Pedagógicos, 5(2), 281-290. 
Cafiero, D. (2005). Leitura como processo. Ceale.

Camilo, T. M., \& Ometto, C. B. D. C. N. (2017). O trabalho com leitura em um sexto ano do ensino fundamental: limites e possibilidades. Leitura: teoria \& prática, 35(70), 101-116. https://doi.org/10.34112/2317-0972a2017v35n70p101-116

Oliveira, C. M. A., Scarpa, D. L., Sasseron, L. H., Sedano, L., Silva, M. B., Capecchi, M. C. V. M., Abib, M. L. V. S. \& Briccia, V. (2013). Ciências e leitura: um ecnontro possível. In A. M. P. Carvalho (Org.), Ensino de Ciências por Investigação: Condições para a implementação em sala de aula (pp. 77-91). Cengage Learning.

Cook, L. K., \& Mayer, R. E. (1988). Teaching readers about the structure of scientific text. Journal of Educational Psychology, 80(4), 448-456. https://doi.org/10.1037/00220663.80.4.448

Coscarelli, C. V. (2002). Entendendo a leitura. Revista de estudos da linguagem, 10(1), 7-27. http://dx.doi.org/10.17851/2237-2083.10.1.7-27

Delizoicov, D., Angotti, J. A., \& Pernambuco, M. M. (2002). Ensino de ciências: fundamentos e métodos. Cortez.

Evangelista, S., \& Jerônimo, I. C. (2014). Os desafios da escola pública paranaense na perspectiva do professor PDE. Secretaria de Educação do Paraná.

Ferraz, A. S. D., Duarte, J. S., Cunha, F. M., Filho, C. B., \& Arruda, M. S. P. (07-10 de novembro, 2001). Leitura e compreensão de textos nos livros didáticos de Ciências: um problema no significado das palavras. III Encontro Nacional de Pesquisa em Educação em Ciências (ENPEC), Atibaia, São Paulo.

Flor, C. C. F., \& Cassiani, S. (08-13 de novembro, 2009). Histórias de leituras de estudantes em aulas de química no ensino médio e as condições de produção de sentidos. VII Encontro Nacional de Pesquisa em Educação em Ciências (ENPEC), Florianópolis, Santa Catarina.

Franco, S. A. P., \& Fernandes, G. F. G. (2016). Mafalda: possibilidades de leitura na perspectiva Histórico Crítica. Revista Educação e Cultura Contemporânea, 13(34), 145161.

Francisco, C. A., \& Queiroz, S. L. (28 de novembro a 03 de dezembro, 2005). Análise dos trabalhos apresentados nos encontros de debates sobre o ensino de química de 1999 a 2003. V Encontro Nacional de Pesquisa em Educação em Ciências (ENPEC). Bauru.

Freitas, C., \& Rocha, R. (24-27 de novembro, 2015). Textos multimodais no ensino de biologia: entendendo a leitura dos alunos. X Encontro Nacional de Pesquisa em Educação em Ciências (ENPEC), Águas de Lindóia, São Paulo.

Gambarini, C., \& Bastos, F. (25-29 de novembro, 2003). Leitura no ensino de Ciências: A postura de professores e alunos perante o texto escrito. IV Encontro Nacional de Pesquisa em Educação em Ciências (ENPEC), Bauru, São Paulo. 
Giraldelli, C. G. C. M., \& Almeida, M. J. P. M. (28 de novembro a 03 de dezembro, 2005). Mediações possíveis numa leitura coletiva para o ensino de ciências e ambiente no ensino fundamental. V Encontro Nacional de Pesquisa em Educação em Ciências (ENPEC), Bauru, São Paulo.

Giraldi, P. M., \& Cassiani, S. (05-09 de dezembro, 2011). Leituras e escritas de estudantes do ensino fundamental: entre a paráfrase e a polissemia. VIII Encontro Nacional de Pesquisa em Educação em Ciências (ENPEC), Campinas, São Paulo.

Giraldi, P. M. G., \& Cassiani, S. (08-13 de novembro, 2009). Leitura em aulas de ciências: análise de condições de produção. VII Encontro Nacional de Pesquisa em Educação em Ciências (ENPEC), Florianópolis, Santa Catarina.

Gomes, S. (2017). Avaliação das capacidades de leitura. Educar em Revista, 33(63), $221-$ 236. https://doi.org/10.1590/0104-4060.46325

Green, J. L., \& Meyer, L. A. (1991). The embeddedness of reading in classroom life: reading as a situated process. In C. Baker \& A. Luke(Org.), Toward a critical sociology of reading pedagogy (pp. 141-160). John Benjamin.

Guaita, R. I., \& Gonçalves, F. P. (10-14 de novembro, 2013). As contribuições de uma estratégia de leitura em uma perspectiva progressista para a educação química. IX Encontro Nacional de Pesquisa em Educação em Ciências (ENPEC), Águas de Lindóia, São Paulo.

Guzzetti, B. J., Snyder, T. E., \& Glass, G. V. (1992). Promoting conceptual change in science: Can texts be used effectively? Journal of reading, 35(8), 642-649. http://www. jstor.org/stable/40032156

Hayden, H. E., \& Eades-Baird, M. (2016). What Can Students do With the Words They Know? An ELA Teacher Takes on Science. Literacy Research: Theory, Method, and Practice, 65(1), 182-199. https://doi.org/10.1177\%2F2381336916661531

Heineke, A. J., Smetana, L., \& Carlson S., J. (2019). A qualitative case study of field-based teacher education: One candidate's evolving expertise of science teaching for emergent bilinguals. Journal of Science Teacher Education, 30(1), 80-100. https://doi.org/10.1080/ 1046560X.2018.1537058

Jiménez, A. M. P., \& Brocos, P. (2015). Desafíos metodológicos en la investigación de la argumentación en la enseñanza de las ciencias. Ensaio Pesquisa em Educação em Ciências, 17, 139-159. https://doi.org/10.1590/1983-2117201517s08

Kleiman, A. (1996). Leitura: ensino e pesquisa. Pontes.

Kleiman, A. (2004). Texto e Leitura: Aspectos cognitivos da Leitura. Pontes.

Koch, A., \& Eckstein, S. G. (1991). Improvement of reading comprehension of physics texts by students' question formulation. International Journal of Science Education, 13(4), 473-485. https://doi.org/10.1080/0950069910130410 
Lana, M. P. C., \& Silva, F. A. R. (2019). O ensino de ciências nos anos iniciais com o aporte da literatura infantil de Monteiro Lobato. ACTIO: Docência em Ciências, 4(3), 185-203. http://dx.doi.org/10.3895/actio.v4n3.10448

Lerner, D. (2002). Ler e escrever na escola: O real o Possível e o Necessário. Artmed.

Ludke, M., \& André, M. E. (2011). Pesquisa em educação: abordagens qualitativas. Em Aberto, 5(31), 43-48. https://doi.org/10.24109/2176-6673.emaberto.5i31.1605

Matos, M. (03-06 de julho, 2017). Atividades de leitura e escrita em aulas de ciências: reflexões sobre linguagem e conhecimento escolar. XI Encontro Nacional de Pesquisa em Educação em Ciências (ENPEC), Florianópolis, Santa Catarina.

Mendes, R. M., \& Miskulin, R. G. S. (2017). A análise de conteúdo como uma metodologia. Cadernos de Pesquisa, 47(165), 1044-1066. https://doi.org/10.1590/198053143988

Meireles, S. M., Okuma, V. K., \& Munford, D. (24-27 de novembro, 2015). Leitura de textos de não-ficção em aulas de ciências: explorando a diversidade de formas de engajamento. X Encontro Nacional de Pesquisa em Educação em Ciências (ENPEC), Águas de Lindóia, São Paulo.

Miranda, S. A. A., Briccia, V., Leandro, L., \& Santos, J. N. (24-27 de novembro, 2015). A literatura infantil no ensino de ciências: possibilidades para formação leitora. X Encontro Nacional de Pesquisa em Educação em Ciências (ENPEC), Águas de Lindóia, São Paulo.

Moreira, A. L. O. R., Santos, J. N., \& Franzoi, C. (05-09 de dezembro, 2011). Projeto leitura: Uma alternativa para a percepção ambiental e o ensino de ciências. VIII Encontro Nacional de Pesquisa em Educação em Ciências (ENPEC), Campinas, São Paulo.

Mortimer, E. F., Chagas, A. N., \& Alvarenga, V. T. (1998). Linguagem científica versus linguagem comum nas respostas escritas de vestibulandos. Investigações em ensino de ciências, 3(1), 7-19. https://www.if.ufrgs.br/cref/ojs/index.php/ienci/article/view/622

Mortimer, E. F. (1998). Multivoicedness and univocality in classroom discourse: an example from theory of matter. International Journal of Science Education, 1, 67-82. https://doi.org/10.1080/0950069980200105

Neves, L. A. S., \& Souza, A. R. (25-29 de novembro, 2003). Analogias e metáforas no ensino de ciências: análise da inserção de um livro paradidático de mecânica quântica e a sua leitura por alunos do ensino médio. IV Encontro Nacional de Pesquisa em Educação em Ciências (ENPEC), Bauru, São Paulo.

Nigro, R. G., \& Trivelato, S. L. (2010). Leitura de textos de ciências de diferentes gêneros: um olhar cognitivo-processual. Investigações em Ensino de Ciências, 15(3), 553-573. https://www.if.ufrgs.br/cref/ojs/index.php/ienci/article/view/262

Nigro, R. G., \& Trivelato, S. F. (2012). Knowledge, its application, and attitudes associated with the reading of diverse genres of science texts. International Journal of Science Education, 34(16), 2529-2564. https://doi.org/10.1080/09500693.2012.711916 
Nigro, R. G. N., \& Trivelato, S. L. F. (28 de novembro a 03 de dezembro, 2005). Textos no ensino-aprendizagem de ciências: primeiras evidências a favor de um modelo de trabalho baseado em teorias de leitura. V Encontro Nacional de Pesquisa em Educação em Ciências (ENPEC), Bauru, São Paulo.

Nigro, R. G., \& Trivelato, S. L. F. (26 de novembro a 02 de dezembro, 2007). Uma avaliação da aprendizagem de conhecimentos associada à leitura de textos de ciências de diferentes gêneros. VI Encontro Nacional de Pesquisa em Educação em Ciências (ENPEC), Florianópolis, Santa Catarina.

Norris, S. P., \& Phillips, L. M. (2003). How literacy in its fundamental sense is central to scientific literacy. Science education, 87(2), 224-240. https://doi.org/10.1002/sce.10066

Oliveira, K. L., Suehiro, A. C. B., \& Santos, A. A. A. (2004). Avaliação da aprendizagem no ensino superior: estudo da relação com a compreensão em leitura. In C. Machado, L. S. Almeida, M. Gonçalves \& V. Ramalho (Orgs.), Avaliação Psicológica: Formas e Contextos (pp. 217-223). Psiquilíbrios Edições.

Özdem, Y., Cakiroglu, J., Ertepinar, H., \& Erduran, S. (2017). The pedagogy of argumentation in science education: science teachers instructional practices. International Journal of Science Education, 39(11), 1443-1464. https://doi.org/10.1080 /09500693.2017.1336807

Pagliarini, C. R., \& Almeida, M. J. P. M. (24-27 de novembro, 2015). Sentidos produzidos por estudantes do ensino médio na leitura de um texto de cientista do início da física quântica. X Encontro Nacional de Pesquisa em Educação em Ciências (ENPEC), Águas de Lindóia, São Paulo.

Pereira, F. B., \& Lima, S. A. (2018). Leitura e Ensino de Ciências: Estratégias de Leitura para o Gênero Textual Mapa. Experiências em Ensino de Ciências, 13(3), 33-47.

Pérez, D. G., Montoro, I. F., Alís, J. C., Cachapuz, A., \& Praia, J. (2001). Para uma imagem não deformada do trabalho científico. Ciência \& Educação, 7(2), 125-153.

Pinto, A. A. P., \& Raboni, P. C. A. (28 de novembro a 03 de dezembro, 2005). Concepções de ciência na literatura infantil brasileira: conhecer para explorar possibilidades. V Encontro Nacional de Pesquisa em Educação em Ciências (ENPEC), Bauru, São Paulo.

Ramos, J. E. F., Kimura, R., Souza, R. M., \& Piassi, L. P. (24-27 de novembro, 2015). Clube do livro científico: aproximações entre ciência e literatura na escola. X Encontro Nacional de Pesquisa em Educação em Ciências (ENPEC), Águas de Lindóia, São Paulo.

Ribeiro, N. A., \& Munford, D. (10-14 de novembro, 2013). Leitura em uma sala de aula de ciências: a construção social de conexões intertextuais em uma unidade didática de ecologia. IX Encontro Nacional de Pesquisa em Educação em Ciências (ENPEC), Águas de Lindóia, São Paulo.

Ricon, A. E., \& Almeida, M. J. P. M. (1991). Ensino da física e leitura. Leitura: teoria e 
prática, 10(18), 7-16.

Sasseron, L. H. (2015). Alfabetização científica, ensino por investigação e argumentação: relações entre ciências da natureza e escola. Ensaio Pesquisa em Educação em Ciências, 17(spe), 49-67. https://doi.org/10.1590/1983-2117201517s04

Sasseron, L. H., \& Carvalho, A. M. P. (2011). Alfabetização científica: uma revisão bibliográfica. Investigações em ensino de ciências, 16(1), 59-77. https://www.if.ufrgs.br/ cref/ojs/index.php/ienci/article/view/246

Sasseron, L. H., \& Carvalho, A. M. P. (2008). Alfabetização científica no ensino fundamental: estrutura e indicadores deste processo em sala de aula (Tesde de Doutorado, Universidade de São Paulo, São Paulo, São Paulo).

Scheid, N. M. J., Persich, G. D. O., \& Krause, J. C. (08-13 de novembro, 2009). Concepção de natureza da Ciência e a educação científica na formação inicial. VII Encontro Nacional de Pesquisa em Educação em Ciências (ENPEC), Florianopólis, Santa Catarina.

Sedano, L., \& Carvalho, A. M. P. de. (24-27 de novembro, 2015). Ler e compreender nas aulas de ciências: uma análise. X Encontro Nacional de Pesquisa em Educação em Ciências (ENPEC), Águas de Lindóia, São Paulo.

Sedano, L., Souza, C. B. S., \& Vaillant, F. A. R. (2019). Leitura e ensino de Ciências nos Anos Iniciais: Análise das pesquisas do ENPEC (1997-2017). ACTIO: Docência em Ciências, 4, 610-628. http://dx.doi.org/10.3895/actio.v4n3.10613

Setlik, J., \& Higa, I. (2019). Contribuições e Dificuldades de Práticas de Leitura e Escrita para Ensinar e Aprender Física no Ensino Médio: Reflexões à Luz da Cultura Escolar. Revista Brasileira de Pesquisa em Educação em Ciências, 19, 449-482. https://doi. org/10.28976/1984-2686rbpec2019u449482

Sillos, A. E., \& Santos, W. L. P. (10-14 de novembro, 2013). Percepções de alunos do ensino médio sobre o livro didático de química. IX Encontro Nacional de Pesquisa em Educação em Ciências (ENPEC), Águas de Lindóia, São Paulo.

Silva, A. C., \& Almeida, M. J. P. M. (10-14 de novembro, 2013). Uma leitura de divulgação científica sobre ressonância magnética no ensino médio. IX Encontro Nacional de Pesquisa em Educação em Ciências (ENPEC), Águas de Lindóia, São Paulo.

Silva, T. D. A. (2019). Ensino de ciências por investigação: contribuições da leitura para a alfabetização científica nos anos iniciais. ACTIO: Docência em Ciências, 4(3), 346-366. http://dx.doi.org/10.3895/actio.v4n3.10526

Silveira, J. C. L., Castro M. E. C., \& Machado, A. H. (2015). Leitura em sala de aula de ciências como uma prática social dialógica e pedagógica. Ensaio Pesquisa em Educação em Ciências, 17(3), 633-656. https://doi.org/10.1590/1983-21172015170305

Soares, A. G., \& Coutinho, F. A. (26 de novembro a 02 de dezembro, 2007). Leitura, discussão e produção de textos como recurso didático para o letramento científico. VI Encontro Nacional de Pesquisa em Educação em Ciências (ENPEC), Florianópolis, 
Santa Catarina.

Soares, M. (2008). Letramento-um tema em três gêneros. Autêntica.

Sidone, O. J. G., Haddad, E. A., \& Mena, C. J. P. (2016). A ciência nas regiões brasileiras: evolução da produção e das redes de colaboração científica. Transinformação, 28(1), 15-31. https://doi.org/10.1590/2318-08892016002800002

Simas, F. J. P., Cassiani, S., \& Flôr, C. C. (24-27 de novembro, 2013). O pisa: leituras de ciências e tecnologias no ensino fundamental. IX Encontro Nacional de Pesquisa em Educação em Ciências (ENPEC), Águas de Lindóia, São Paulo.

Solé, I. (1996). Estratégias de leitura. Artmed.

Targino, A. R. L., \& Giordan, M. (03-06 de julho, 2017). Prática de leitura em uma aula de química: literatura e experimentação. XI Encontro Nacional de Pesquisa em Educação em Ciências (ENPEC), Florianópolis, Santa Catarina.

Wenzel, J. S. (2017). A Apropriação da Linguagem Científica Escolar e as Interações Discursivas Estabelecidas em Sala de Aula como Modo de Aprender Ciências. Revista Transmutare, 2(1), 18-33. https://periodicos.utfpr.edu.br/rtr/article/view/6036

Yore, L. D., Bisanz, G. L. \& Hand, B. M. (2003). Examining the literacy component of science literacy: 25 years of language arts and science research. Internacional Journal of Science Education, 25(6), 689-725. https://doi.org/10.1080/09500690305018

Zômpero, A. F., \& Laburú, C. E. (05-09 de dezembro, 2001). Significados estabelecidos por alunos da quinta série, a partir da leitura de texto e figura representativa de fotossíntese, utilizadas durante atividade de investigação. VIII Encontro Nacional de Pesquisa em Educação em Ciências (ENPEC), Campinas, São Paulo. 


\section{Caroline Batista Silva de Souza}

Universidade Estadual de Santa Cruz (UESC/Ilhéus-BA) Ilhéus, Bahia, Brasil cbssouza@uesc.br

Luciana Sedano

Universidade Estadual de Santa Cruz (UESC/Ilhéus-BA) Ilhéus, Bahia, Brasil luciana.sedano@gmail.com

Editor Responsável

Alessandro Gomes

Manifestação de Atenção às Boas Práticas Científicas e de Isenção de Interesse

Os autores declaram ter cuidado de aspectos éticos ao longo do desenvolvimento da pesquisa e não ter qualquer interesse concorrente ou relações pessoais que possam ter influenciado o trabalho relatado no texto. 